\title{
Review Article \\ The Role of Mitochondrial Reactive Oxygen Species in Cardiovascular Injury and Protective Strategies
}

\author{
Danina M. Muntean,, ${ }^{1,2}$ Adrian Sturza, ${ }^{1,2}$ Maria D. Dănilă, ${ }^{1,2}$ \\ Claudia Borza, ${ }^{1,2}$ Oana M. Duicu, ${ }^{1,2}$ and Cristian Mornos ${ }^{3}$ \\ ${ }^{1}$ Department of Pathophysiology, Victor Babeș University of Medicine and Pharmacy, 2 Eftimie Murgu Square, \\ 300041 Timisoara, Romania \\ ${ }^{2}$ Center for Translational Research and Systems Medicine, Victor Babeș University of Medicine and Pharmacy, 2 Eftimie Murgu Square, \\ 300041 Timisoara, Romania \\ ${ }^{3}$ Department of Cardiology-2nd Cardiology Clinic, Victor Babeş University of Medicine and Pharmacy, 2 Eftimie Murgu Square, \\ 300041 Timisoara, Romania
}

Correspondence should be addressed to Oana M. Duicu; oanaduicu@umft.ro

Received 21 February 2016; Revised 29 March 2016; Accepted 30 March 2016

Academic Editor: Mohanraj Rajesh

Copyright (C) 2016 Danina M. Muntean et al. This is an open access article distributed under the Creative Commons Attribution License, which permits unrestricted use, distribution, and reproduction in any medium, provided the original work is properly cited.

Ischaemia/reperfusion (I/R) injury of the heart represents a major health burden mainly associated with acute coronary syndromes. While timely coronary reperfusion has become the established routine therapy in patients with ST-elevation myocardial infarction, the restoration of blood flow into the previously ischaemic area is always accompanied by myocardial injury. The central mechanism involved in this phenomenon is represented by the excessive generation of reactive oxygen species (ROS). Besides their harmful role when highly generated during early reperfusion, minimal ROS formation during ischaemia and/or at reperfusion is critical for the redox signaling of cardioprotection. In the past decades, mitochondria have emerged as the major source of ROS as well as a critical target for cardioprotective strategies at reperfusion. Mitochondria dysfunction associated with I/R myocardial injury is further described and ultimately analyzed with respect to its role as source of both deleterious and beneficial ROS. Furthermore, the contribution of ROS in the highly investigated field of conditioning strategies is analyzed. In the end, the vascular sources of mitochondria-derived ROS are briefly reviewed.

\section{Introduction}

Ischaemia/reperfusion ( $\mathrm{I} / \mathrm{R})$ injury of the heart represents a major health burden mainly associated with acute coronary syndromes. Each year, myocardial infarction (MI) is responsible for the death of millions of persons and, more importantly, due to the aging of the population, represents the first cause of chronic heart failure worldwide [1]. Thus, it is not surprising that it has been predicted, already 10 years ago, that more than $40 \%$ of US population will suffer from heart failure as end stage of cardiovascular pathologies by the year 2030 [2].

Timely coronary reperfusion by either thrombolysis or primary coronary artery angioplasty has become the established routine therapy in patients with ST-elevation MI
(STEMI) which effectively decreases infarct size and reduces mortality [3]. Paradoxically, restoration of the blood flow into an ischaemic area is always accompanied by myocardial injury [4]. In fact, several distinctive pathophysiological changes have been systematically associated with revascularization. These changes, collectively denominated "reperfusion injury," comprise both (i) reversible (sublethal) events such as reperfusion-induced arrhythmias and myocardial stunning (prolonged but fully reversible contractile dysfunction) and (ii) irreversible (lethal) ones, namely, the accelerated necrosis in tissue that has been already irreversibly injured (the "oxygen paradox") [5], the induction of microvascular obstruction (responsible for the no-reflow phenomenon), and the lethal reperfusion injury (death of cardiomyocytes that were potentially viable at the end of the ischaemic event, that 
is, prior to reperfusion) (reviewed in [6-8]). Although the existence of this last major event was at the time a matter of debate $[9,10]$, substantial experimental evidence supported, firstly, the fact that irreversible reperfusion injury (through necrosis, apoptosis, and autophagy) exists [11] and, secondly, the concept that early reperfusion represents a window of opportunity for the delivery of adjunctive therapies capable of preventing cardiomyocyte death [12-14].

During the past four decades, a tremendous research effort was put forward to elucidate the pathophysiology of I/R injury and identify strategies that are able to provide cardioprotection at reperfusion, that is, to enhance the amount of myocardium salvaged by timely restoration of the blood flow $[6,7,14,15]$. In this respect, the mitochondrion is the organelle that has been unanimously indicated as the major culprit responsible for the development of cardiomyocyte death [11, 16-19] and, also, the primary target in protecting the heart against the deleterious effects of reperfusion injury [20-23].

Among the main mechanisms that underlie mitochondrial dysfunction and, ultimately, cardiomyocyte death in the setting of I/R injury, namely, calcium dysregulation, ATP depletion, release of proapoptotic proteins, and oxidative stress, the last issue, that is, excessive formation of reactive oxygen species (ROS) with the subsequent damage of cell constituents, plays a central role as it is able to trigger and/or potentiate each of the other mentioned mechanisms [24].

However, in neither field has the well-known principle stated by Paracelsus "dosis sola venenum facit" "the dose alone makes the poison") been more true as in the case of redox biology. Indeed, while increased oxygen radical production is the central mechanism involved in postischaemic myocardial injury, minimal ROS formation is critical for the redox signaling of cardioprotection (reviewed in [25-31]).

Basic cardiovascular research has witnessed the discovery of a myriad of ways to protect the heart/cardiomyocytes in various experimental models of $I / R$ injury. Despite the fact that clinical application of these strategies has been thus far limited [32], the development of specific molecules targeting mitochondria of living cells for therapeutic gain is a rapidly evolving field and a number of drugs have already entered clinical testing [21, 33-36].

Mitochondria dysfunction associated with postischaemic myocardial injury is further described and ultimately analyzed with respect to its role as source of both deleterious and beneficial reactive oxygen species in the setting of I/R injury and for cardioprotective signaling, respectively. Last but not least, the potential vascular sources of mitochondria-derived ROS are briefly reviewed.

\section{Mitochondria Dysfunction in Ischaemia/Reperfusion Injury: Historical Perspective}

Mitochondria occupy a fixed fractional volume ( $21 \%$ of the total heart mass) in mammalians and are strategically placed in the vicinity of myofibrils to ensure the delivery of a huge amount of ATP (ten times the cardiac mass) which is largely generated via oxidative phosphorylation and required for the myocardial contraction that occurs within a wide workload range [37]. Since the heart is strictly dependent on aerobic metabolism, it is not surprising that cardiac pathology is intimately intricated with mitochondrial impairment in the setting of myocardial I/R injury. Moreover, heart is primarily a postmitotic organ and, therefore, the death of cardiomyocytes is the major phenomenon that underlies this organ pathology.

Most of our research knowledge regarding the structural and biochemical changes elicited by experimental ischaemia and reperfusion comes from the pioneering studies started in the late 60 s by Robert Jennings. In his seminal papers, he provided a clear definition of lethal ischaemic injury as being "the ischaemic injury of sufficient severity and duration that the involved cells will continue to degenerate and become necrotic despite reoxygenation by reperfusion of arterial blood" $[38,39]$. This definition points to the gradual pattern of the process, in which irreversibly injured ischaemic cardiomyocytes will ultimately progress to the loss of membrane integrity and necrotic cell death. At the end of prolonged ischaemic episodes (e.g., $40 \mathrm{~min}$ in dogs), mitochondria in irreversibly injured cells contain one or more small (80$150 \mu \mathrm{m}$ ) amorphous matrix densities, being ascribed as "the most reliable indicator of irreversibility" [40, 41]. Interestingly, these dense matrix deposits (consisting primarily of lipids and little calcium) were considered a characteristic feature not only of ischaemia-related irreversible injury of the heart but also of drug and toxic-induced injury in liver and kidney [41]. Besides the gradual pattern of progression to death, when reperfused in vivo after prolonged periods of ischaemia, cardiomyocytes undergo an abrupt irreversible injury characterized by hypercontracture and a rapid increase in permeability of the sarcolemmal membrane responsible for the release of intracellular enzymes [42], observations relevant for the phenomenon of lethal reperfusion injury. Mitochondria in these cells showed diffuse swelling and accumulated a second type of matrix densities, distinct from the amorphous ones already present at the time of reperfusion; these granular dense bodies contained a large amount of calcium precipitated as an initially undefined form of calcium phosphate $[40,41]$. As noticed in a critical review, the most important finding of the classical studies was that the hallmark events of irreversible injury, that is, hypercontracture and calcium overload, required functional (coupled) mitochondria in order to occur [43]. Indeed, hypercontracture of sarcomeres into contraction bands [44] and mitochondrial accumulation of calcium as well as the enzymes release were all lessened by inhibiting mitochondrial respiration with the subsequent decrease in ATP synthesis (reviewed in $[45,46]$ ). Accordingly, it was evident already almost 4 decades ago that restoration of mitochondrial function in myocardial cells after severe ischaemia was the major culprit for the doubleedged sword effect of reperfusion, since ATP production via oxidative phosphorylation was mandatory for the recovery of cardiomyocytes but appeared to also contribute to the postischaemic cell death. Despite the thoroughly performed experiments, it should be mentioned that Jennings and Ganote refrained themselves from affirming a causal relationship 
between the "observed changes in mitochondrial structure and function and the death of the myocardial cell" due to the technical limitations at that time [40].

Similarly, these authors acknowledged the role of excessive production of oxygen free radicals at reperfusion and their toxic effects on both myocardium and vasculature; however, they admitted only the possibility that in the case of irreversibly injured myocytes "free radicals might accelerate the degradation of dead cells, but not kill any cells which were otherwise viable" [42]. Moreover, 15 years ago, both the existence and, more importantly, the clinical relevance of the reperfusion injury were strongly questioned [47].

The disrupted mitochondrial electron system has been already identified by the mid-70s as a potential source of oxyradicals (in particular superoxide) in the setting of $I / R$ injury; the process is further contributed by a decrease in the free radical scavenging capacity due to the loss of mitochondrial reduced superoxide dismutase and reduced glutathione (reviewed in [48]). The uncontrolled reactivation of mitochondria upon oxygenation with subsequent ROS generation has also been considered responsible for the peroxidation of cardiac lipids, increased sarcolemmal permeability, and enzyme release; the events have been prevented in the presence of either superoxide dismutase or reduced glutathione administered at the end of hypoxia and during reoxygenation [49].

Indeed, as Halliwell mentioned, it was the time when "the field of free radicals and antioxidants was simple: free radicals are bad, antioxidants must be good" [50]. The huge amount of research carried in the past decades in the field provided a progressive change of the paradigm, namely, that "too many oxidants are bad, but some may be good" [44]. Undoubtedly, free radicals account for the harmful effects (oxidative attack of proteins, lipids, and DNA) only when rapidly generated in elevated concentrations (e.g., during the postischaemic reperfusion) whereas in low or moderate amounts they act as signaling molecules with a critical role in the regulation of several fundamental physiological and adaptive processes (including cardioprotection).

\section{Mitochondria as Sources of Harmful ROS}

3.1. Oxidative Stress: Old and New Definitions. Oxidative stress has been classically defined as the spatiotemporal, quantitative imbalance between increased ROS formation (prooxidant stress) and decreased ROS removal (antioxidant defense) that is responsible for cellular damage $[51,52]$. It has to be mentioned that the term does not refer only to the overproduction of "true" free radicals (molecules containing one or more unpaired electrons), such as superoxide anion (the primary ROS) and hydroxyl radical, but also to the increased generation of highly reactive nonradical derivatives, mainly hydrogen peroxide, peroxynitrite, and singlet oxygen [53].

However, ten years ago Jones proposed a new definition of stress as being "an imbalance between oxidants and antioxidants in favor of the oxidants, leading to a disruption of redox signaling and control and/or molecular damage," pointing to the crucial role of disrupting the ROS-mediated signal transduction [54]. Moreover, Jones challenged the free radical dependent-oxidative stress theory by postulating the radicalfree "redox hypothesis" according to which oxidative stress occurs via the disruption of thiol pathways due to aberrant generation of nonradical oxidants in distinct subcellular compartments [55]. In this respect, the term has been recently redefined in that oxidative stress should be perceived rather as a subcellular deleterious event than as a global threat to the whole cell [53]. In any case, regardless of the theory, mitochondria are the organelles that lie at the heart of redox biology being at the same time the sources of harmful and beneficial ROS and the main targets for oxidation.

3.2. Mitochondrial Sources of Harmful ROS. Mitochondria consume about $98 \%$ of the inhaled oxygen in order to produce the energy required to sustain life [56]. The increased efficiency of the oxidative phosphorylation in eukaryote cells comes at a price of mitochondrial generation of ROS; thus, ROS production and lethal reperfusion injury appear to be both a sort of "necessary evil" [57, 58].

Mitochondria have been conventionally recognized as the major cellular source for ROS production. Indeed, several expert research groups have systematically studied along the years the mitochondrial origins of ROS; in this respect, the reader is referred to several comprehensive reviews of the topic [59-71]. Moreover, it has to be mentioned that an unbiased estimation of the contribution of mitochondrial sources to oxidative stress in living cells requires not only multiple ROS reporter molecules but also parallel assessment of parameters that may induce artifacts as well as testing conditions that could interfere with the mitochondrial generation of oxidants [72]. What is unequivocally established so far is that ROS can be generated in vitro as either an accidental or an obligatory by-product of mitochondrial metabolism [73]. The former case is best exemplified by a dysfunctional electron transport system (ETS) (due to toxic or stress-related inhibition, mutational damage, and elevation of mitochondrial membrane potential due to metabolic causes) whereas the latter is best exemplified by the increased activity/expression or assembly failure of enzymes with defined metabolic roles [51, 57, 73]. More recently, the group of Koopman suggested that local ROS and/or reactive nitrogen species (RNS) involved are short-term regulation of mitochondrial morphology (fusion and fission) and function via nontranscriptional pathways [74].

There is plethora of experimental evidence supporting the roles of complexes I and III of the ETC as major generators of superoxide, the primary ROS (reviewed in [26, 59-61, 64$66,84]$ and summarized in Table 1). Interestingly, Forkink et al. have recently suggested that the increase in ROS levels is not surpassing the capacity of the antioxidant systems within the cells [153]. In this respect, they demonstrated that chronic inhibition of CI and CIII in HEK293 cells (i) stimulated oxidation of the ROS sensor hydroethidine, (ii) increased cytosolic (but not mitochondrial) $\mathrm{H}_{2} \mathrm{O}_{2}$ levels, and (iii) was not associated with oxidative stress or cell death [153].

In the past years, several studies have also demonstrated the role of complex II defect in ${ }^{\circ} \mathrm{O}_{2}{ }^{-}$overproduction (Table 1). 
TABLE 1: Mitochondrial sources of ROS generation.

\begin{tabular}{|c|c|}
\hline ROS sources & $\begin{array}{l}\text { Experimental model: } \\
\text { references }\end{array}$ \\
\hline \multicolumn{2}{|c|}{ Inner membrane } \\
\hline $\begin{array}{l}\text { CI (NADH dehydrogenase): } \\
\text { inner side }\end{array}$ & $\begin{array}{l}\text { (i) Bovine hearts: [75-83] } \\
\text { (ii) Rat heart: }[80,84-86] \\
\text { (iii) Rat brain: }[60,86,87] \\
\text { (iv) Rat lung: }[88] \\
\text { (v) Rat liver: }[84] \\
\text { (vi) Rat skeletal muscle: } \\
\text { [84, 89-91] } \\
\text { (vii) Cell cultures: [79] } \\
\text { (viii) Human brain: [87] }\end{array}$ \\
\hline $\begin{array}{l}\text { CII (succinate dehydrogenase): } \\
\text { inner side }\end{array}$ & $\begin{array}{l}\text { (i) Rat heart: }[92,93] \\
\text { (ii) Bovine heart: [94-96] } \\
\text { (iii) Rat brain: [97] } \\
\text { (iv) Rat skeletal muscle: [98] } \\
\text { (v) Yeast: }[99] \\
\text { (vi) E. coli: [100] }\end{array}$ \\
\hline $\begin{array}{l}\text { CIII (ubiquinol-cytochrome c } \\
\text { reductase): inner and outer side }\end{array}$ & $\begin{array}{l}\text { (i) Bovine heart: } \\
\text { [95, 96, 101, 102] } \\
\text { (ii) Rat heart: }[84,103,104] \\
\text { (iii) Rat liver: }[84,105] \\
\text { (iv) Rat brain: }[104] \\
\text { (v) Rat skeletal muscle: }[84] \\
\text { (vi) Mouse skeletal muscle: } \\
\text { [106] } \\
\text { (vii) R. capsulatus strains: } \\
\text { [107] }\end{array}$ \\
\hline $\begin{array}{l}\text { Hyperphosphorylation of CIV } \\
\text { (cytochrome } c \text { oxidase) }\end{array}$ & $\begin{array}{l}\text { (i) Rabbit hearts and mouse } \\
\text { monocyte macrophages: [108] }\end{array}$ \\
\hline $\begin{array}{l}\text { Glycerophosphate } \\
\text { dehydrogenase (a.k.a. } \\
\text { glycerol-3-phosphate } \\
\text { dehydrogenase, a.k.a. mGPDH): } \\
\text { outer side }\end{array}$ & $\begin{array}{l}\text { (i) Mouse heart, brain, and } \\
\text { kidney: [109] } \\
\text { (ii) Hamster brown adipose } \\
\text { tissue: [110] } \\
\text { (iii) Drosophila: [111] }\end{array}$ \\
\hline $\begin{array}{l}\text { Dihydroorotate dehydrogenase } \\
\text { (DHO): outer side }\end{array}$ & $\begin{array}{l}\text { (i) Rat brain \& liver: [112] } \\
\text { (ii) Rat skeletal muscle: [113] } \\
\text { (iii) Rat tissues (skeletal } \\
\text { muscle, liver, GI tract, etc.): } \\
\text { [114] } \\
\text { (iv) Cell lines: [115] } \\
\text { (v) Human skin and kidney: } \\
\text { [114] }\end{array}$ \\
\hline \multicolumn{2}{|c|}{ Intermembrane space } \\
\hline $\begin{array}{l}\text { p66 } \\
\text { Shc) }\end{array}$ & $\begin{array}{l}\text { (i) Mouse liver: [116] } \\
\text { (ii) Mouse aorta: [117] }\end{array}$ \\
\hline
\end{tabular}

\section{Matrix}

Aconitase (mitochondrial- (m-) aconitase)

(i) Bovine heart: [118]

Alpha-ketoglutarate dehydrogenase complex (KGDHC, a.k.a. 2-oxoglutarate dehydrogenase)

(i) Bovine heart: [119]

(ii) Mouse brain: [120]

Outer membrane

Cytochrome $b 5$ reductase

(i) Human brain tissue: [121]
TABle 1: Continued.

\begin{tabular}{ll}
\hline ROS sources & $\begin{array}{l}\text { Experimental model: } \\
\text { references }\end{array}$ \\
\hline & (i) Rat brain: [122] \\
& (ii) Rat hearts: [123] \\
& (iii) Mouse liver, kidney, and \\
& heart: [124-126] \\
Monoamine oxidases (MAO-A & (iv) Mouse aorta: [127] \\
and MAO-B) & (v) Rat aorta: [128] \\
& (vi) Cell line: [129] \\
& (vii) Human atrial samples: \\
& {$[130]$} \\
\hline
\end{tabular}

Among these, the groups of Quinlan et al. [98] and Siebels and Dröse [94] have studied ROS generation at complex II in artificial conditions, such as a low concentration of succinate and inhibition of respiratory chain downstream to CII $[94,98]$. Finally, ROS generation by complex IV was demonstrated to be rather relevant in pathological conditions by Prabu et al. since hyperphosphorylation of complex IV on ischaemic hearts increases the electron leakage and, therefore, the ${ }^{\circ} \mathrm{O}_{2}^{-}$production [108].

In addition to the ETS, several other mitochondrial sites (see Table 1) can be also responsible for ROS production in a tissue-specific manner and dependent on the experimental conditions [64]. Moreover, one of the most pertinent observations has been recently formulated by Andreyev et al.; these authors acknowledged the fact that, in line with the observer effect postulated in quantum physics, directly assessing ROS production using the conventional systems is not possible without changing the process [57].

3.3. Mitochondrial ROS Generation in Ischaemic/Reperfused Heart. Physiological, low concentrations of mitochondrial ROS are considered to exert beneficial effects on cardiovascular function [97]. Accordingly, a tight redox control is responsible for cardiomyocyte differentiation and excitation-contraction coupling $[154,155]$. On the contrary, ROS overproduction is responsible for the so-called phenomenon "ROS-induced ROS release" $[70,156]$ or the "kindling radicals" concept $[157,158]$, which postulates that (extra)mitochondrial ROS trigger mitochondrial ROS production, with a pathological impact on (1) cardiac cells via the cellular bioenergetic decline which leads to the impairment of excitation-contraction coupling, arrhythmias, cardiac hypertrophy, apoptosis, necrosis, and fibrosis [71]; (2) endothelial cells, with 2 major effects: (i) the inflammatory vascular reaction involved in the pathogenesis of atherosclerosis, hypertension, and diabetes [159] via the activation of $\mathrm{Ca}^{2+}$-activated potassium channel (KCa channel) coupled with intracellular signaling of PKG-1 $\alpha$ activation in the smooth muscle cells $[160,161]$ and (ii) the coronary collateral growth inhibition [162] via the coronary dilation mediated by the activation of voltage-dependent potassium channels ( Kv channels) and thiol redox-dependent signaling $[163,164]$.

In the setting of $I / R$ injury the contribution of mitochondria-derived ROS to oxidative stress is particularly true for the metabolically active organs, such as heart and 


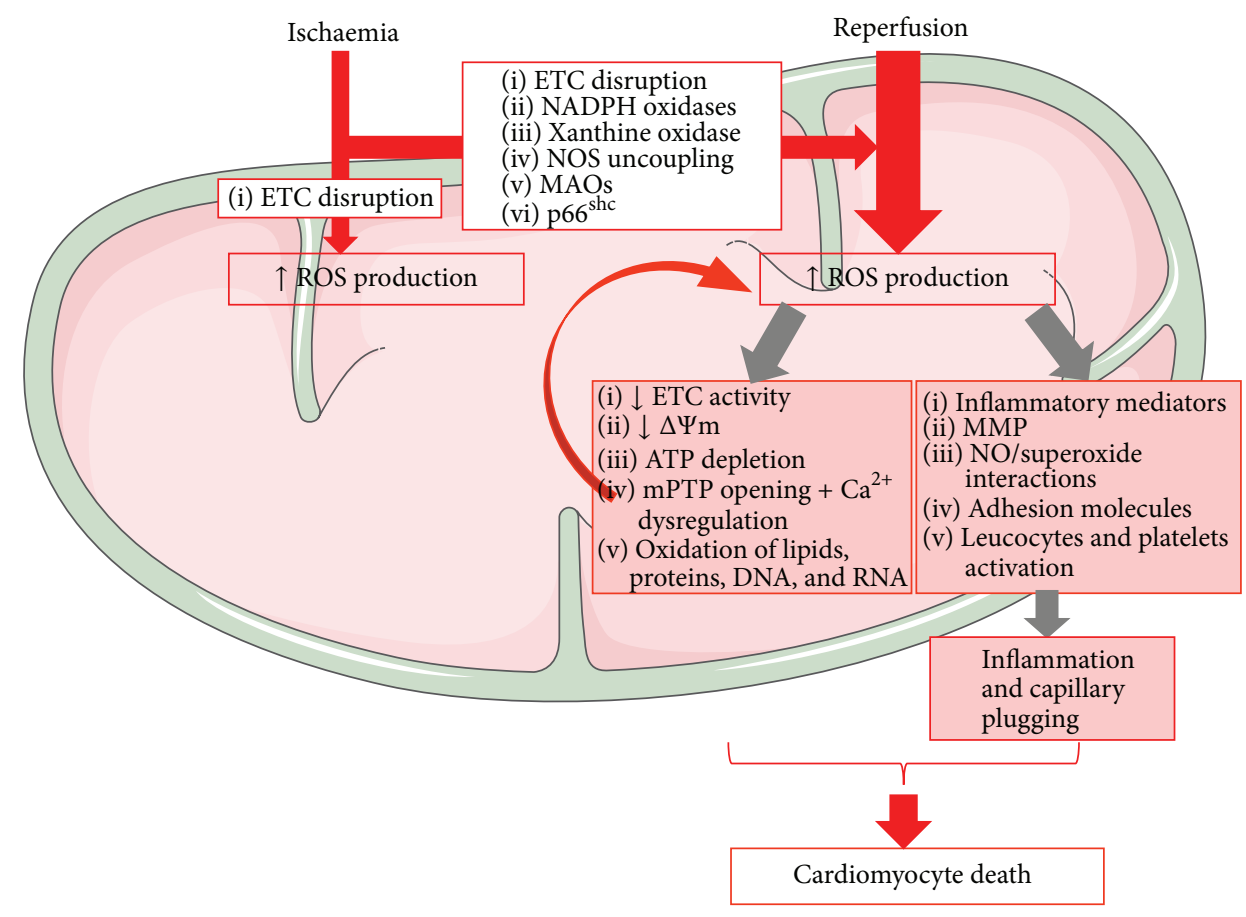

FIGURE 1: Mitochondrial ROS contribution to I/R injury. Cellular hypoxia secondary to ischaemia results in disruption of ETC activity in the IMM (inner mitochondrial membrane) with subsequent ROS production. Increased activity of MAOs, NADPH oxidase, and p66 ${ }^{\text {shc; }}$ conformational changes of xanthine oxidase; and/or NO synthase uncoupling further amplify ROS production upon reoxygenation. Increased mitochondrial ROS damages mtDNA and RNA with ETC impairment. Dysfunctional ETC will amplify ROS generation, leading to a vicious cycle of mitochondrial cumulative damage, decreased mitochondrial membrane potential $\left(\Delta \psi_{m}\right)$ and respiration, mPTP opening with cellular swelling and $\mathrm{Ca}^{2+}$ dysregulation, and oxidation of lipids and proteins. Postischaemic ROS generation also stimulates an inflammatory response, with the release of chemical mediators and expression of adhesion molecules by endothelial cells and leukocytes. ROS-dependent activation of MMPs (matrix metalloproteinases) is also responsible for the functional impairment of several proteins and receptors. The inflammatory response and the activation of leucocytes and platelets trigger the narrowing of capillaries during reperfusion, accelerating the progression towards cardiomyocyte death. (Illustration realized thanks to Servier Medical Art.)

brain [26]. Both hyperoxia (at reperfusion) and, also (albeit counterintuitively), hypoxia (during the ischaemic period) are able to trigger ROS production (Figure 1, [26, 68, 165]). During ischaemia, cardiomyocytes become hypoxic and the mitochondrial ETC complexes are highly reduced; the reaction of the electrons leaking from the respiratory complexes with residual oxygen will generate the superoxide anion. At reperfusion, hyperoxygenation will be associated with marked superoxide and superoxide-downstream ROS (mainly, hydrogen peroxide, peroxynitrite, and the hydroxyl radical) both due to electron leakage and due to a decrease in the detoxification capacity of mitochondria (Figure 1, [71]). An important consequence due to myocardial $\mathrm{I} / \mathrm{R}$ is the change in the mitochondrial balance $\mathrm{NO} /{ }^{\circ} \mathrm{O}_{2}{ }^{-}$, with an increased NO production, subsequent excess of $\mathrm{ONOO}^{-}$synthesis, and an increase of the related protein tyrosine nitration [166]. An enzyme with high susceptibility to oxidative stress is aconitase, whose activity is clearly impaired during myocardial I/R, followed by the increase of hydroxyl radicals release [167], an observation which could be suggestive for using the oxidative inactivation of mitochondrial aconitase activity as an additional marker of myocardial infarction [71].
The major contributor to ROS overproduction during I/R is related to the oxidative impairment of mitochondrial complex I along with a corresponding decrease in NADH-linked state 3 oxygen consumption and enhanced NADH-linked ROS production, respectively $[168,169]$, and reviewed in [23, 71]. During reperfusion, the NADH-ferricyanide reductase activity (the enzymatic activity of $\mathrm{NADH}$ dehydrogenase) is restored, which partially explains the ${ }^{\circ} \mathrm{O}_{2}{ }^{-}$production during reperfusion, since NADH dehydrogenase is one of the major sources for ${ }^{\bullet} \mathrm{O}_{2}{ }^{-}$generation at complex I. Impaired complex I activity during reperfusion might be also responsible for ROS-induced damage of mitochondrial cardiolipin and respiratory supercomplexes that further increases the electron leakage at complex I and induces a vicious cycle of oxidative stress that ultimately leads to mitochondrial dysfunction $[169,170]$. Lastly, an important protein tyrosine nitration of complex I in the postischaemic heart was demonstrated with a subsequent inactivation of complex I [166].

The involvement of complex II in ROS production in ischaemic hearts is unclear, despite the fact that diazoxide or atpenin A5 (specific complex II inhibitors) has been proven to exert cardioprotective effects by activating mitochondrial ATP-sensitive potassium $\left(\mathrm{mK}_{\mathrm{ATP}}\right)$ channels [71]. 
TABLE 2: Potential mechanisms responsible for the decrease in ROS generation.

\begin{tabular}{|c|c|}
\hline Site of action & Mechanism \\
\hline (1) UCP2 or UCP3 overexpression [131-133] & $\begin{array}{l}\text { Reduced mitochondrial ROS production via mitochondrial } \\
\text { uncoupling with subsequent } \Delta \psi \text { depolarization }\end{array}$ \\
\hline (2) Brief transient mPTP opening [134] & $\begin{array}{l}\text { Reduced ROS production and/or release into the cytosol via a } \\
\text { reversible } \Delta \psi \text { depolarization } \\
\text { Observation: a prolonged mPTP opening triggers apoptosis and } \\
\text { cell death }[135,136]\end{array}$ \\
\hline $\begin{array}{l}\text { (3) Recruitment of hexokinase }(\mathrm{HK}) \text { at the mitochondrial outer } \\
\text { membrane [137] }\end{array}$ & $\begin{array}{l}\text { Increased coupled respiration with subsequent reduced electron } \\
\text { leak and ROS production }\end{array}$ \\
\hline (4) Glutathionylation of CII and CV $[92,138,139]$ & Decreased activity of CII and CV \\
\hline $\begin{array}{l}\text { (5) Glutathionylation of the } 51-\mathrm{kDa}(\mathrm{NDUFV} 1) \text { and } 75-\mathrm{kDa} \\
\text { (NDUFS1) CI subunits }[79,81,140,141]\end{array}$ & $\begin{array}{l}\text { Decreased activity of CI } \\
\text { Observation: however, CI inactivation is not necessarily linked to } \\
\text { reduced ROS production since Taylor and collaborators } \\
\text { demonstrated that glutathionylation of CI was associated to } \\
\text { increased superoxide production [142] }\end{array}$ \\
\hline (6) Reduction of electrons input $[143,144]$ & $\begin{array}{l}\text { Lowered cellular glucose uptake and stimulation of pyruvate } \\
\text { conversion to lactate with secretion of the latter into the } \\
\text { extracellular environment }\end{array}$ \\
\hline $\begin{array}{l}\text { (7) Mild uncoupling }[145,146] \text { and inhibition of succinate } \\
\text { dehydrogenase [147] via the action of potassium channel } \\
\text { openers }\end{array}$ & $\begin{array}{l}\text { Inhibition of CI with subsequent reduction of } \mathrm{H}_{2} \mathrm{O}_{2} \text { release into } \\
\text { the cytosol }\end{array}$ \\
\hline
\end{tabular}

Complex III is also considered an important source for mitochondrial ROS production in ischaemic hearts [171], due to increased lipid peroxidation of cardiolipin required for complex III activity [172] and increased protein tyrosine nitration [166]. The electron leakage at complex III was associated with pharmacological preconditioning by diazoxide (the classic mitoK $\mathrm{K}_{\mathrm{ATP}}$ channel opener) via the inhibition of complex II with and transient generation of signaling ROS at complex III [173].

Lastly, complex IV-mediated ROS production can also be enhanced in ischaemic hearts via the activation of mitochondrial protein kinase A (PKA) which increased hyperphosphorylation of complex IV $[108,161]$. Moreover, Spear et al. demonstrated that PKA-mediated depression of complex IV activity was reversed by blocking $\beta 1$-adrenergic receptor activation during $I / R$, with a subsequent reduction of the myocardial injury [167].

Another recently investigated mitochondrial source for ROS generation is represented by monoamine oxidases (MAOs), two isoforms, MAO-A and MAO-B, located on the outer mitochondrial membrane. These FAD-containing dehydrogenases catalyze the electron transfer from the biogenic amines to $\mathrm{O}_{2}$ and constantly generate hydrogen peroxide $\left(\mathrm{H}_{2} \mathrm{O}_{2}\right)$ as by-product. $\mathrm{MAO}$-derived $\mathrm{H}_{2} \mathrm{O}_{2}$ is the primary signaling molecule when generated in minute amounts and becomes harmful when highly generated during conditions associated with oxidative stress [73]. Accordingly, in settings of postischaemic reperfusion or heart failure, the increased activity of MAO-A isoform significantly contributed to the aggravation of myocardial injury [174-177] and progression towards the maladaptive left ventricle hypertrophy and remodeling, respectively $[125,178]$. These studies have unequivocally demonstrated the role of MAO-A in cardiac pathology; however, recent experimental data also reported the presence and contribution of MAO-B isoform to oxidative stress in the murine cardiovascular system $[126,128,179]$. We have recently demonstrated that both MAOs isoforms are expressed in atrial appendages harvested from patients with cardiovascular pathology (i.e., valvular disease and coronary heart disease), with the predominance of the MAO-B isoform (Duicu et al., in press). To date there is only one study in the literature showing that an increased activity of MAO-B is responsible for the induction of mitochondrial dysfunction and cardiac structural/functional alterations in mice with experimentally induced heart failure [126].

3.4. Antioxidant Strategies in Ischaemia/Reperfusion Injury. The mitochondrial antioxidant system is a network of high complexity (the reader is referred to several comprehensive reviews [51, 57, 143]) and comprises 3 major categories: (1) the first one includes superoxide dismutase 2 (MnSOD) and catalase, which exert their ROS neutralizing activity independent of the reducing equivalents; (2) the second one includes peroxiredoxins 3 and 5 ( $\operatorname{Prx} 3$ and $\operatorname{Prx} 5$, located in the mitochondrial matrix), which depend on thioredoxin (Trx) and thioredoxin reductase (TRx2) for their regeneration; (3) the third one includes glutathione peroxidases 1 and 4 (GPX1 and GPX4) and glutaredoxins, which depend on GSH and glutathione reductase (GR) to regenerate GSH [57]. The last two categories of ROS scavengers depend on NADPH, which in turn is regenerated by 3 mitochondrial matrix enzymes: isocitrate dehydrogenase $\left(\mathrm{NADP}^{+}\right.$-linked), malic enzyme, and transhydrogenase [60]. The individual contribution of these enzymes to mitochondrial NADPH regeneration is far from being elucidated [180].

The mechanisms that potentially could underlie the mitigation of ROS generation are listed in Table 2. 
Therapeutic antioxidant approaches against the $I / R$ myocardial injury have been disappointingly ineffective [181184] or even harmful [53], most probably because the applied strategies were not able to distinguish between deleterious and beneficial ROS generation [29] and these differences between animal and human pathological models [185]. However, recent data have proven an enhanced therapeutic efficiency of novel synthetic antioxidants in ameliorating the I/R-linked oxidative stress with a subsequent cardioprotective effect. Such antioxidants include NO-based and vitamin E (MitoVit-E) molecules which are able to sequester antioxidants in mitochondria and Alda 1, a small molecule activator of aldehyde dehydrogenase-2, a mitochondrial enzyme that detoxifies aldehydes involved in myocardial I/R (reviewed in [29]). In bovine aortic endothelial cells exposed to oxidative stress, MitoVit-E significantly decreased ROS production and apoptosis [186], yet it was not neuroprotective in striatal medium-spiny neurons subjected to acute perinatal hypoxicischaemic brain injury [187]. An important disadvantage of MitoVit-E is that its scavenging activity is not regenerated [188]. At variance, mitoquinone (MitoQ) containing the antioxidant coenzyme Q (quinone) is regenerated by ETC after detoxifying ROS and was proven to inhibit mitochondrial oxidative stress in rodent models of I/R [189]. Another synthetic mitochondrial scavenger is the plastoquinone SkQ1, which used in a lower concentration than that of MitoQ was also able to reduce the infarct size and arrhythmias in rats subjected to I/R [190].

Of a particular promise for the inhibition of deleterious ROS induced by $I / R$ injury might be the gene therapy approaches as demonstrated so far by two recent studies that used target upregulation of mitochondrial antioxidant enzymes like MnSOD or matrix peroxiredoxins [191] or overexpressed prosurvival molecules such as aldehyde dehydrogenase-2 microRNAs [192].

\section{Mitochondria as Sources of Beneficial ROS}

Until the 80 s, I/R injury was considered a black or white phenomenon, the cardiomyocytes being provided with no more than two options-recovery or death. However, starting with the $80 \mathrm{~s}$, it became apparent that myocardial cells exposed to a variety of insults, including ischaemia, have an innate ability to mount several cardioprotective responses and an inherent program for survival. In the early days of myocardial I/R research, it was found that while the reintroduction of oxygen through reperfusion was essential for recovery, this also caused a burst of free radicals finally leading to myocardial injury [193]. Based on the concept that ROS only have deleterious effects, the administration of free radical scavengers was thought to be an appropriate solution in this situation. Several studies reported protective effects of this strategy, which unfortunately were surprisingly not supported by other independent laboratories [194]. Nowadays, it is largely accepted that some ROS represent intracellular mediators in physiological processes like vasodilation, cell growth, and angiogenesis and redox signaling is an important determinant of epigenetic and genetic regulation of cellular function. It has now become abundantly clear that, in cardioprotection against I/R injury, ROS present a delicate beneficial to deleterious switch [28] and this cross talk to and from mitochondria [157] might be favorable since the inhibition of a single source of ROS partially or even completely abrogated the oxidative stress [127].

The most powerful intrinsic mechanism of cardioprotection is represented by ischaemic preconditioning (IPC) which has been reported to cause adaptation to ischaemia in, virtually, all experimental settings from cell cultures to mammals. This strategy was first established by Murry et al. in 1986 [195] and describes the ability of brief periods of nonlethal ischaemia alternated with reperfusion to protect the heart from a subsequent prolonged lethal or "index" ischaemia. In 2003, the term postconditioning (PostC) was coined by the group of Vinten-Johansen to define a series of brief mechanical interruptions of reperfusion that were early applied within the first 3 minutes of reperfusion, elicited an anti-infarct protection comparable to the one induced by IPC [196]. The introduction of this appealing term as a novel strategy to limit lethal reperfusion injury, even if criticized by some authors who considered it as a form of modified reperfusion or compared it to "an old wine in a new bottle" [197], has the huge merit of resuscitating the concept that more myocardium can be salvaged by adding adjunct therapies to the early reperfusion. IPC and PostC require direct intervention on the heart, which may be challenging in some clinical situations. Remote ischaemic conditioning (RIC) was developed as a procedure performed by applying brief cycles of nonlethal $\mathrm{I} / \mathrm{R}$ in a vascular territory remote from the heart. Although it is similarly cardioprotective to IPC and PostC, the fact that it is implemented at a distance from the organ of interest constitutes an evident advantage [198]. All these strategies represent endogenous self-defense mechanisms that are dependent on ROS generation. The identification of the most relevant sources of ROS and the threshold at which they lose their potentially protective effect and become damaging to cellular function and integrity still represents an unmet need in the field of cardioprotection [27].

4.1. Ischaemic Preconditioning. To date, no other strategy aimed at reducing $\mathrm{I} / \mathrm{R}$ injury has proven itself to be more effective than IPC and thousands of paper tackled the mechanisms underlying its protective effect with numerous signaling molecules being identified as participating in the signal transduction sequence [199]. Among these, the generation of sublethal amounts of ROS during the short cycles of ischaemia and/or reperfusion has been consistently reported to be the trigger of IPC, possibly through the oxidation of protective cytosolic kinases [200]. The direct consequence of minute ROS generation prior to the prolonged ischaemia was the triggering of a "ROS-induced ROS decrease" response during the postischaemic reperfusion in every species tested. The observation that the deleterious burst of ROS upon reperfusion is reduced when IPC is applied has been demonstrated 20 years ago [201] and is still valid until today [202]. 
In addition, administration of exogenous ROS induces a protective effect similar to IPC [203], whereas antioxidants decrease or abolish cardioprotection [204, 205].

Mitochondria have emerged as the major source of ROS generation within the cardiac myocytes in the setting of preconditioning [206]. The PKCe activated by IPC induces the stimulation of mitochondrial $\mathrm{K}_{\text {ATP }}$ channels causing a slight increase in $\mathrm{H}_{2} \mathrm{O}_{2}$ production which eventually leads to the inhibition of the mitochondrial permeability transition pore (mPTP) [207], seemingly the final effector of IPC [208]. Within this cascade of events, there might be a direct interaction between ROS and MPTP components or the sublethal oxidative stress can set in motion signaling pathways that decrease mitochondrial susceptibility to MPTP opening [27]. Also, a small level of ROS can be generated through a brief opening of the MPTP that may play an important role in cardioprotection [209]. In line with this observation, it has been reported that the inhibition of CyP$\mathrm{D}$ results in abolition of ROS formation and of IPC-related cardioprotection, respectively [210].

In addition, it may be that all forms of cardiomyocyte stress lead to ROS signaling and that this could represent a mechanism for gaining ischaemic tolerance, as data suggests that hyperthermic preconditioning is reliant on ROS production [211].

An important source of mitochondrial $\mathrm{H}_{2} \mathrm{O}_{2}$ generation is the activation of MAO-A (as discussed in Section 3) during reperfusion with the occurrence of apoptosis in isolated cardiac myocytes; indeed, in lower concentrations, $\mathrm{H}_{2} \mathrm{O}_{2}$ was found to be partly responsible for the cardioprotective effect of IPC [212]. Supporting this claim, MAO inhibition in the settings of IPC has been reported to abolish cardioprotection (Di Lisa, unpublished observations, cited by [213]). However, in a recent study in isolated rat hearts subjected to a preconditioning protocol, we have demonstrated that bracketing the IPC episodes with MAO inhibitors did not interfere with the antinecrotic protection but potentiated the postischaemic functional recovery [214].

4.2. Ischaemic Postconditioning. Even though IPC is indeed the most efficient strategy, postconditioning (PostC) also proved to afford cardioprotection, although slightly less so than the former in terms of decreasing the infarct size. Penna et al. were the first to notice that ROS are needed to trigger PostC-related protection too [215]. In line with this observation, other studies have proven that PostC-mediated protection was abolished in the presence of ROS scavengers at the beginning of reperfusion $[215,216]$.

Cardioprotection is also possibly mediated by the prevention of mPTP opening by acidosis during the PostC cycles, while the intermittent bursts of oxygen throughout the brief I/R episodes allow mitochondria to produce just enough ROS in a moment when other enzymes, responsible for the generation of massive quantities of free radicals, are not yet reactivated. The consequent activation of the PKC pathway leads to the sensitization of adenosine receptors, signaling via the RISK pathway [199], and, finally, the prevention of $\mathrm{mPTP}$ formation even after the $\mathrm{pH}$ returned to normal
[213]. Although all the mentioned evidence supports the idea that PostC-related cardioprotection is dependent on redox signaling, it is also apparent that the type, concentration, and the sources of ROS may be key factors in triggering protection at the time of reperfusion [213]. Contrary to the limited clinical applicability of IPC, PostC applied to humans in the cardiac catheterization laboratory has provided encouraging results by two clinical studies $[217,218]$, whereas others found no cardioprotective effects [219, 220]. Such discrepancies might be the result of different inclusion/exclusion criteria and the differences in the PostC chosen protocols. Thereby, the results of the DANAMI-3 trial (NCT01435408) designed to investigate postconditioning in STEMI patients are awaited this year with real interest [221].

\subsection{Remote Ischaemic Conditioning. Remote ischaemic con-} ditioning (RIC) was firstly described in 1993 by Przyklenk et al. [222] who noted that brief episodes of I/R applied in one region of the heart are protective for remote virgin myocardium in a separate myocardial territory. The mechanisms behind RIC are very complex and occur in three interrelated stages: (1) the I/R stimulus induces the synthesis of protective factors in the remote organ; (2) the protective signal is transmitted through a complex neurohumoral interaction to the target organ; (3) the events taking place in the target organ result in the protective effect.

Presumably, the signaling pathways activated in the remote and the target organ, respectively, are similar to those described in IPC and PostC [198]. Again, ROS production is part of the signaling cascade involved. Once the cardioprotective signal resulting from the ischaemic remote organ reaches the heart, it binds to G-protein cell surface coupled receptors which activate intracellular kinases like PKC- $\varepsilon$ and other signaling molecules such as ROS and the mitochondrial $\mathrm{K}_{\mathrm{ATP}}$ channel [223]. It has been demonstrated that IPC and remote ischaemic preconditioning (RIPC) both rely on free radicals to induce cardioprotection, as $N$-2-mercaptopropionyl glycine, an antioxidant, is capable of completely blocking the beneficial effect of RIC when ischaemia is induced by infrarenal occlusion of the rat aorta [224]. Also, in a model of RIPC obtained by occlusion of the mouse femoral artery, the ischaemia applied in the remote organ induced $S$-nitrosation of mitochondrial complex I in cardiomyocytes, which resulted in a reduction of $\operatorname{ROS}$ (i.e., $\mathrm{H}_{2} \mathrm{O}_{2}$ ) in the reperfused myocardium at risk [225].

As in the case of PostC, RIPC has been successfully translated to humans and recent pilot studies showed that it is able to improve clinical outcome and prognosis (excellently reviewed by [221]). In order to confirm these proof-ofconcept studies, two multicentre trials of RIPC are currently ongoing, namely, NCT01857414 (CONDI II trial) and NCT02342522 (ERIC-PPCI trial).

Despite the successful results in animal models (reviewed in [30]) and in several pilot human studies (see above), the results of the cardioprotective trials targeting mitochondria have been rather disappointing (Table 3). 
TABLE 3: Cardioprotective strategies targeting mitochondria in clinical trials.

\begin{tabular}{|c|c|c|}
\hline Trial & Strategy & Results \\
\hline NCT01502774 (CIRCUS trial) & $\begin{array}{l}\text { A bolus injection of CsA } \\
\text { administered at the onset of } \\
\text { myocardial reperfusion in patients } \\
\text { with anterior ST-segment-elevation } \\
\text { MI (STEMI) }\end{array}$ & $\begin{array}{l}\text { Worsened heart failure during the } \\
\text { initial hospitalization, } \\
\text { rehospitalization for heart failure, } \\
\text { and adverse left ventricular } \\
\text { remodeling at } 1 \text { year in } 59.0 \% \text { of the } \\
395 \text { patients randomized to } \\
\text { cyclosporine and } 58.1 \% \text { of the } 396 \\
\text { individuals randomized to placebo } \\
{[148]}\end{array}$ \\
\hline NCT01374321 (MITOCARE trial) & $\begin{array}{l}\text { I.v. bolus administration of } \\
\text { TRO40303 (an inhibitor of mPTP } \\
\text { opening) in STEMI patients } \\
\text { undergoing primary PCI } \\
\text { (percutaneous coronary } \\
\text { intervention) }\end{array}$ & $\begin{array}{l}\text { TRO } 40303 \text { did not show any } \\
\text { protective effects as compared to } \\
\text { placebo in preventing reperfusion } \\
\text { injury in STEMI patients treated } \\
\text { with primary PCI [149] }\end{array}$ \\
\hline NCT01572909 (EMBRACE STEMI trial) & $\begin{array}{l}\text { MTP-131 (a cell-permeable peptide } \\
\text { that preserves the integrity of } \\
\text { cardiolipin, enhances mitochondrial } \\
\text { energetics, and improves myocyte } \\
\text { survival during reperfusion in } \\
\text { animal models) administration for } \\
1 \mathrm{~h} \text { among first-time anterior STEMI } \\
\text { subjects undergoing primary PCI } \\
\text { for a proximal or mid left anterior } \\
\text { descending (LAD) artery occlusion }\end{array}$ & $\begin{array}{l}\text { Administration of MTP-131 was not } \\
\text { associated with a significant } \\
\text { reduction in infarct size or clinical } \\
\text { outcomes [150] }\end{array}$ \\
\hline NCT01584453 (NITRITE-AMI trial) & $\begin{array}{l}\text { Intracoronary injection of nitrite } \\
\text { during primary PCI in STEI } \\
\text { patients }\end{array}$ & $\begin{array}{l}\text { The phase II showed that } \\
\text { intracoronary nitrite infusion did } \\
\text { not change the infarct size. Yet, in a } \\
\text { subgroup of patients with TIMI } \\
\text { flow } \leq 1 \text {, nitrite reduced infarct size } \\
\text { and MACE and improved } \\
\text { myocardial salvage index indicating } \\
\text { a follow-up with the phase III of the } \\
\text { clinical trial [151] }\end{array}$ \\
\hline NCT01388504 (NIAMI trial) & $\begin{array}{l}\text { Intravenous sodium nitrite } \\
\text { administration immediately prior to } \\
\text { PCI in patients with acute STEMI }\end{array}$ & $\begin{array}{l}\text { Myocardial infarct size did not } \\
\text { differ between nitrite and placebo } \\
\text { groups. There were no significant } \\
\text { differences in plasma troponin I and } \\
\text { CK area under the curve, left } \\
\text { ventricular volumes, and ejection } \\
\text { fraction measured at } 6-8 \text { days and } \\
\text { at } 6 \text { months and final infarct size } \\
\text { measured at } 6 \text { months [152] }\end{array}$ \\
\hline
\end{tabular}

\section{Mitochondria-Derived ROS and Endothelial Dysfunction}

The mitochondrial content in the endothelial cells is rather poor as compared to other cells, for example, $2-6 \%$ of the rat cell volume versus $28 \%$ in hepatocytes or $32 \%$ in cardiomyocytes $[226,227]$. At variance from cardiomyocytes, endothelial mitochondrial content and energy requirements are relatively reduced, glycolysis being the main source of ATP production [228]. Nowadays these organelles are considered major players in both cell signaling and vascular disease [188]. Moreover, mitochondrial cellular distribution represents a key factor for its function. In this view, the group of Gutterman demonstrated in endothelial cells isolated from human coronary arterioles that mitochondria are anchored to the cytoskeleton being thus responsible for ROS release in response to cell deformation by shear stress [229]. Another relevant study sustaining this theory demonstrated that pulmonary artery exposed to hypoxia induced a retrograde mitochondrial movement requiring microtubules and the microtubule motor protein dynein, changes that lead to a perinuclear clustering of mitochondria [230]; moreover, this mitochondrial redistribution was associated with ROS accumulation in the nucleus, which was further reduced by nocodazole which destabilized the microtubules and, thus, suppressed the perinuclear clustering of mitochondria [230]. 
In recent years, an increasing attention has been payed to the alterations of mitochondrial fusion and fission, due to their harmful consequences on cellular bioenergetics and endothelial dysfunction in the settings of cardiovascular disorders [74, 231, 232].

A wealth of clinical and experimental studies unequivocally demonstrated that endothelial dysfunction represents a central event in the pathogenesis of cardiovascular diseases (recently reviewed in [233]). Risk factors, such as aging, hypercholesterolemia, hyperglycemia, smoking, infections, and hypoxia, alter the mitochondrial membrane potential $\left(\Delta \psi_{m}\right)$, with a subsequent contribution to excessive mitochondrial ROS production [233]. If the membrane is depolarized, complexes I and III show an increased activity in order to restore membrane potential, thus leading to ROS generation [226]. Metabolic disease states associated with high nutrient availability and low ATP demand are characterized by membrane hyperpolarization which also results in excessive ROS [227]. The consequential modifications of mitochondrial components affect the mtDNA, proteins, and lipids which in turn will stimulate ROS production, creating thus a vicious cycle that promotes vascular disease [234, 235]. Moreover, the mtDNA damage is responsible for the alteration of the ETS components expression, leading to an increased ROS production [236].

Apart from complexes I and III of the respiratory chain, another important source of mitochondria-derived ROS in endothelial cells is nicotinamide adenine dinucleotide phosphate (NADPH) oxidase 4 (NOX-4), which is the most highly expressed Nox family member in the endothelial layer of vasculature, being localized in many intracellular compartments, including mitochondria [237, 238]. Endothelial cells and basal ROS production, mainly $\mathrm{H}_{2} \mathrm{O}_{2}$ (rather than ${ }^{\circ} \mathrm{O}_{2}{ }^{-}$) as stated by [239], require NOX-4 and its homolog NOX-2 [238]. More recently, it was suggested that NOX-4 has rather a preventive function, since it protected the vasculature during ischaemic or inflammatory stress [240]. Thus, the contribution of NOX-4 to ROS signaling, angiogenesis, oxidative stress, endothelial dysfunction, and inflammation processes is far from being fully elucidated [240-244].

Another mitochondrial source of ROS is the growth factor adapter protein $\mathrm{p} 66^{\text {shc }}$. In physiological conditions, $\mathrm{p} 66^{\text {shc }}$ is included in a high-molecular-weight inhibitory protein complex located in the mitochondrial matrix or even in the cytoplasm. Circumstances associated with proapoptotic signals, such as hypoxia, activate $\mathrm{p} 66^{\text {shc }}$ which migrates in the mitochondrial intermembrane space, where, through the oxidation of cytochrome $\mathrm{c}$, it generates $\mathrm{H}_{2} \mathrm{O}_{2}$ [116]. Moreover, p $66^{\text {shc }}$ can become active via phosphorylation by protein kinase $\mathrm{C}$ in conditions associated with hyperglycemia, contributing thus to diabetic endothelial dysfunction [117, 245]. p6 $6^{\text {shc }}$ deletion in models of vascular injury has yielded beneficial effects $[117,246]$, supporting thus the statement about its implication in oxidative stress [227].

Mitochondrial ATP-sensitive potassium channel $\left(\right.$ mitoK $\left._{\mathrm{ATP}}\right)$ represents a regulator of mitochondrial free oxygen radicals. Although it has not been the focus of interest in vascular dysfunction so far, its activation seems to protect cultured endothelial cells from ischaemic cell death and to maintain vasodilating capacity in Langendorffperfused guinea-pig hearts suffering from I/R injury $[247,248]$. Furthermore, glibenclamide, a nonselective $K_{\text {ATP }}$ channel blocker, abolished the IPC-induced preservation of endothelium-dependent dilation in the human forearm, while the mito $_{\mathrm{ATP}}$ opener diazoxide mimicked the IPC protection $[249,250]$. These potassium channels also demonstrated the ROS-induced ROS release theory, since ROS produced by another cellular structure acted by opening mitoK $\mathrm{K}_{\mathrm{ATP}}$, stimulating the generation of mitochondrial ROS $[157,251]$. It might be, thus, reasonable to assume that the inhibition of these channels might be protective. As in the case of cardiomyocytes, the phenomenon of ROS-induced ROS release can equally contribute to the pathogenesis of endothelial dysfunction [252].

Lastly, $\mathrm{H}_{2} \mathrm{O}_{2}$ generated by MAO-A in vascular smooth muscle cells contributes to serotonin-induced vasoconstriction [253]. Although it was clearly demonstrated that endothelial cells express MAOs [254], the exact role of these enzymes in modulation of endothelial function has not been fully characterized. Recently, we have described the role of MAOs as mediators of endothelial dysfunction in two murine models of acute (induced with lipopolysaccharide, LPS) and chronic (induced with angiotensin II, AII) [127] oxidative stress or after the induction of experimental diabetes [128]. Both isoforms increased the expression of vascular MAOs with subsequent high $\mathrm{H}_{2} \mathrm{O}_{2}$ generation. This mechanism was deemed responsible for the induction of oxidative stress, altered level of cGMP with a central role in NO-mediated signaling, and a consecutive impairment of aortic rings relaxation [127]. It is important to note that all changes induced by MAOs activation were reversed by the MAO$\mathrm{A}$ and MAO-B inhibitors [127], proving thus the contribution of mitochondria-derived ROS to endothelial dysfunction.

Reperfusion following ischaemia is associated with an increased endothelial generation of ROS and endothelin and a reduced availability of nitric oxide. This latter event promotes neutrophil adhesion to the vascular endothelium and platelet aggregation, which, coupled with the effect of endothelin, will eventually lead to vasoconstriction which is responsible for the no-reflow phenomenon; the adhesion of neutrophils will further enhance ROS release from the endothelium and neutrophils [255]. ROS production represents, thus, an important path in mitochondrial signaling [227], which explains the huge interest in the elucidation of their sources and regulatory mechanisms.

Obviously, the nature of mitochondrial ROS signaling in endothelial cells is still a matter of debate. It may be that the significance of mitochondrial ROS in endothelial cell signaling varies according to vascular bed and risk factor burden [256]. Accordingly, there is evidence that dilation of human cardiac arterioles depends on ETC-derived ROS [229] and that antioxidant therapy blunted the dilation of the healthy human brachial artery [257]. On the other hand, in coronary arteries of atherosclerotic patients, $\mathrm{H}_{2} \mathrm{O}_{2}$ scavengers 
improved endothelium-dependent dilation [258], an effect also noticed in diabetic freshly isolated arterioles treated with mitochondria-targeted antioxidants [259].

In conclusion, targeting vascular ROS definitely represents an important research direction in order to alleviate endothelial dysfunction [260].

\section{Conclusion}

Despite the unequivocal beneficial effects of reperfusion in ceasing the progression of irreversible damage, it is largely accepted nowadays that (i) reperfusion is a doubleedged sword as it is able to induce per se the myocardial lethal reperfusion injury which paradoxically alleviates the beneficial effects of revascularization and (ii) there is an unmet need and a strong interest in developing clinically effective cardioprotective interventions, which are able to further reduce infarct size in association with revascularization procedures. Mitochondrial dysfunction and the resulting oxidative stress are central in the pathogenesis of I/R injury and the drugs that can antagonize cardiomyocyte death by modulating mitochondrial function have started to be systematically investigated in clinical setting. Indeed, novel antioxidant compounds selectively targeting mitochondria appear to be an effective strategy to protect the heart against the deleterious effects of both ischaemic and reperfusion injury, two sides of the same coin. However, since the signaling mechanisms mediating I/R-induced mitochondrial dysfunction are diverse, a combination of pharmacological compounds or coadministration of drugs acting simultaneously on distinct targets should be envisaged.

\section{Competing Interests}

The authors disclose that there are no competing interests.

\section{Acknowledgments}

This study was supported by the University Grant no. PIIIC1-PCFI-2014/2015-04.

\section{References}

[1] A. S. Go, D. Mozaffarian, V. L. Roger et al., "Heart disease and stroke statistics-2014 update: a report from the American Heart Association," Circulation, vol. 129, no. 3, pp. e28-e292, 2014.

[2] C. D. Mathers and D. Loncar, "Projections of global mortality and burden of disease from 2002 to 2030," PLoS Medicine, vol. 3, no. 11, article e442, 2002.

[3] G. M. Fröhlich, P. Meier, S. K. White, D. M. Yellon, and D. J. Hausenloy, "Myocardial reperfusion injury: looking beyond primary PCI," European Heart Journal, vol. 34, no. 23, pp. 17141722, 2013.

[4] E. Braunwald and R. A. Kloner, "Myocardial reperfusion: a double-edged sword?" The Journal of Clinical Investigation, vol. 76, no. 5, pp. 1713-1719, 1985.
[5] D. J. Hearse, "Ischemia, reperfusion, and the determinants of tissue injury," Cardiovascular Drugs and Therapy, vol. 4, supplement 4, pp. 767-776, 1990.

[6] S. R. J. Maxwell and G. Y. H. Lip, "Reperfusion injury: a review of the pathophysiology, clinical manifestations and therapeutic options," International Journal of Cardiology, vol. 58, no. 2, pp. 95-117, 1997.

[7] D. M. Yellon and D. J. Hausenloy, "Myocardial reperfusion injury," The New England Journal of Medicine, vol. 357, no. 11, pp. 1074-1135, 2007.

[8] R. B. Jennings, "Historical perspective on the pathology of myocardial ischemia/reperfusion injury," Circulation Research, vol. 113, no. 4, pp. 428-438, 2013.

[9] R. A. Kloner, "Does reperfusion injury exist in humans?" Journal of the American College of Cardiology, vol. 21, no. 2, pp. 537-545, 1993.

[10] G. Heusch and R. Schulz, "Little evidence for lethal reperfusion injury to cardiomyocytes," Journal of Thrombosis and Thrombolysis, vol. 4, no. 1, pp. 111-112, 1997.

[11] S. B. Ong and A. B. Gustafsson, "New roles for mitochondria in cell death in the reperfused myocardium," Cardiovascular Research, vol. 94, no. 2, pp. 190-196, 2012.

[12] R. J. Diaz and G. J. Wilson, "Modifying the first minute of reperfusion: potential for myocardial salvage," Cardiovascular Research, vol. 62, no. 1, pp. 4-6, 2004.

[13] H. M. Piper, Y. Abdallah, and C. Schäfer, "The first minutes of reperfusion: a window of opportunity for cardioprotection," Cardiovascular Research, vol. 61, no. 3, pp. 365-371, 2004.

[14] D. J. Hausenloy and D. M. Yellon, "Myocardial ischemiareperfusion injury: a neglected therapeutic target," The Journal of Clinical Investigation, vol. 123, no. 1, pp. 92-100, 2013.

[15] D. Garcia-Dorado, A. Rodríguez-Sinovas, M. Ruiz-Meana, and J. Inserte, "Protection against myocardial ischemia-reperfusion injury in clinical practice," Revista Española de Cardiología, vol. 67, no. 5, pp. 394-404, 2014.

[16] F. Di Lisa, "Mitochondrial contribution in the progression of cardiac ischemic injury," IUBMB Life, vol. 52, no. 3-5, pp. 255$261,2002$.

[17] A. L. Moens, M. J. Claeys, J. P. Timmermans, and C. J. Vrints, "Myocardial ischemia/reperfusion-injury, a clinical view on a complex pathophysiological process," International Journal of Cardiology, vol. 100, no. 2, pp. 179-190, 2005.

[18] D. N. Silachev, E. Y. Plotnikov, I. B. Pevzner et al., "The mitochondrion as a key regulator of ischaemic tolerance and injury," Heart Lung and Circulation, vol. 23, no. 10, pp. 897-904, 2014.

[19] A. P. Halestrap and A. P. Richardson, "The mitochondrial permeability transition: a current perspective on its identity and role in ischaemia/reperfusion injury," Journal of Molecular and Cellular Cardiology, vol. 78, pp. 129-141, 2015.

[20] P. Bernardi and F. Di Lisa, “The mitochondrial permeability transition pore: molecular nature and role as a target in cardioprotection," Journal of Molecular and Cellular Cardiology, vol. 78, pp. 100-106, 2015.

[21] D. Morin, T. Hauet, M. Spedding, and J.-P. Tillement, "Mitochondria as target for antiischemic drugs," Advanced Drug Delivery Reviews, vol. 49, no. 1-2, pp. 151-174, 2001.

[22] A. M. Walters, G. A. Porter Jr., and P. S. Brookes, "Mitochondria as a drug target in ischemic heart disease and cardiomyopathy," Circulation Research, vol. 111, no. 9, pp. 1222-1236, 2012. 
[23] A. K. Camara, M. Bienengraeber, and D. F. Stowe, "Mitochondrial approaches to protect against cardiac ischemia and reperfusion injury," Frontiers in Physiology, vol. 2, article 13, 2011.

[24] J. L. Zweier and M. A. H. Talukder, "The role of oxidants and free radicals in reperfusion injury," Cardiovascular Research, vol. 70, no. 2, pp. 181-190, 2006.

[25] F. Di Lisa and P. Bernardi, "Mitochondria and ischemiareperfusion injury of the heart: fixing a hole," Cardiovascular Research, vol. 70, no. 2, pp. 191-199, 2006.

[26] D. N. Granger and P. R. Kvietys, "Reperfusion injury and reactive oxygen species: the evolution of a concept," Redox Biology, vol. 6, pp. 524-551, 2015.

[27] F. Di Lisa, M. Canton, A. Carpi et al., "Mitochondrial injury and protection in ischemic pre-and postconditioning," Antioxidants \& Redox Signaling, vol. 14, no. 5, pp. 881-891, 2011.

[28] F. Tullio, C. Angotti, M.-G. Perrelli, C. Penna, and P. Pagliaro, "Redox balance and cardioprotection," Basic Research in Cardiology, vol. 108, no. 6, article 392, 2013.

[29] T. Kalogeris, Y. Bao, and R. J. Korthuis, "Mitochondrial reactive oxygen species: a double edged sword in ischemia/reperfusion vs preconditioning," Redox Biology, vol. 2, no. 1, pp. 702-714, 2014.

[30] O. M. Duicu, D. Angoulvant, and D. M. Muntean, "Cardioprotection against myocardial reperfusion injury: successes, failures, and perspectives," Canadian Journal of Physiology and Pharmacology, vol. 91, no. 8, pp. 657-662, 2013.

[31] F. Altamirano, Z. V. Wang, and J. A. Hill, "Cardioprotection in ischaemia-reperfusion injury: novel mechanisms and clinical translation," Journal of Physiology, vol. 593, no. 17, pp. 3773$3788,2015$.

[32] H. A. Cabrera-Fuentes, C. Alba-Alba, J. Aragones et al., "Meeting report from the 2nd International Symposium on New Frontiers in Cardiovascular Research. Protecting the cardiovascular system from ischemia: between bench and bedside," Basic Research in Cardiology, vol. 111, article 7, 2016.

[33] J. S. Armstrong, "Mitochondria-directed therapeutics," Antioxidants \& Redox Signaling, vol. 10, no. 3, pp. 575-578, 2008.

[34] R. A. Smith, R. C. Hartley, H. M. Cocheme, and M. P. Murphy, "Mitochondrial pharmacology," Trends in Pharmacological Sciences, vol. 33, no. 6, pp. 341-352, 2012.

[35] C. Reily, T. Mitchell, B. K. Chacko, G. A. Benavides, M. P. Murphy, and V. M. Darley-Usmar, "Mitochondrially targeted compounds and their impact on cellular bioenergetics," Redox Biology, vol. 1, no. 1, pp. 86-93, 2013.

[36] J. P. G. Sluijter, G. Condorelli, S. M. Davidson et al., "Novel therapeutic strategies for cardioprotection," Pharmacology \& Therapeutics, vol. 144, no. 1, pp. 60-70, 2014.

[37] R. S. Balaban, "Perspectives on: SGP symposium on mitochondrial physiology and medicine: metabolic homeostasis of the heart," The Journal of General Physiology, vol. 139, no. 6, pp. 407414, 2012.

[38] R. B. Jennings and W. B. Wartman, "Production of an area of homogeneous myocardial infarction in the dog," AMA Archives of Pathology, vol. 63, no. 6, pp. 580-585, 1957.

[39] R. B. Jennings, C. E. Ganote, and K. A. Reimer, "Ischemic tissue injury," The American Journal of Pathology, vol. 81, no. 1, pp. 179198, 1975.

[40] R. B. Jennings and C. E. Ganote, "Mitochondrial structure and function in acute myocardial ischemic injury," Circulation Research, vol. 38, supplement 1, no. 5, pp. 80-91, 1976.
[41] A. C. Shen and R. B. Jennings, "Myocardial calcium and magnesium in acute ischemic injury," The American Journal of Pathology, vol. 67, no. 3, pp. 417-440, 1972.

[42] V. J. Richard, C. E. Murry, R. B. Jennings, and K. A. Reimer, "Oxygen-derived free radicals and postischemic myocardial reperfusion: therapeutic implications," Fundamental \& Clinical Pharmacology, vol. 4, no. 1, pp. 85-103, 1990.

[43] F. Di Lisa, R. Menabò, M. Canton, and V. Petronilli, "The role of mitochondria in the salvage and the injury of the ischemic myocardium," Biochimica et Biophysica Acta (BBA)Bioenergetics, vol. 1366, no. 1-2, pp. 69-78, 1998.

[44] B. Halliwell, "Free radicals and antioxidants: updating a personal view," Nutrition Reviews, vol. 70, no. 5, pp. 257-265, 2012.

[45] C. E. Ganote and J. P. Kaltenbach, "Oxygen-induced enzyme release: early events and a proposed mechanism," Journal of Molecular and Cellular Cardiology, vol. 11, no. 4, pp. 389-406, 1979.

[46] R. S. Vander Heide, J. P. Angelo, R. A. Altschuld, and C. E. Ganote, "Energy dependence of contraction band formation in perfused hearts and isolated adult myocytes," The American Journal of Pathology, vol. 125, no. 1, pp. 55-68, 1986.

[47] R. A. Kloner, K. Przyklenk, and P. Whittaker, "Deleterious effects of oxygen radicals in ischemia/reperfusion. Resolved and unresolved issues," Circulation, vol. 80, no. 5, pp. 1115-1127, 1989.

[48] J. M. McCord, "Free radicals and myocardial ischemia: overview and outlook," Free Radical Biology and Medicine, vol. 4, no. 1, pp. 9-14, 1988.

[49] Y. Gauduel, P. Menasche, and M. Duvelleroy, "Enzyme release and mitochondrial activity in reoxygenated cardiac muscle: relationship with oxygen-induced lipid peroxidation," General Physiology and Biophysics, vol. 8, no. 4, pp. 327-340, 1989.

[50] B. Halliwell, "The wanderings of a free radical," Free Radical Biology \& Medicine, vol. 46, no. 5, pp. 531-542, 2009.

[51] A. Y. Andreyev, Y. E. Kushnareva, and A. A. Starkov, "Mitochondrial metabolism of reactive oxygen species," Biochemistry (Moscow), vol. 70, no. 2, pp. 200-214, 2005.

[52] W. Dröge, "Free radicals in the physiological control of cell function," Physiological Reviews, vol. 82, no. 1, pp. 47-95, 2002.

[53] H. H. Schmidt, R. Stocker, C. Vollbracht et al., "Antioxidants in translational medicine," Antioxidants \& Redox Signaling, vol. 23, no. 14, pp. 1130-1143, 2015.

[54] D. P. Jones, "Redefining oxidative stress," Antioxidants \& Redox Signaling, vol. 8, no. 9-10, pp. 1865-1879, 2006.

[55] D. P. Jones, "Radical-free biology of oxidative stress," American Journal of Physiology -Cell Physiology, vol. 295, no. 4, pp. C849C868, 2008.

[56] M. R. Duchen, "Mitochondria in health and disease: perspectives on a new mitochondrial biology," Molecular Aspects of Medicine, vol. 25, no. 4, pp. 365-451, 2004.

[57] A. Y. Andreyev, Y. E. Kushnareva, A. N. Murphy, and A. A. Starkov, "Mitochondrial ROS metabolism: 10 years later," Biochemistry, vol. 80, no. 5, pp. 517-531, 2015.

[58] B. Ibanez, V. Fuster, J. Jiménez-Borreguero, and J. J. Badimon, "Lethal myocardial reperfusion injury: a necessary evil?" International Journal of Cardiology, vol. 151, no. 1, pp. 3-11, 2011.

[59] J. F. Turrens, "Mitochondrial formation of reactive oxygen species," The Journal of Physiology, vol. 552, part 2, pp. 335-344, 2003.

[60] Y. Liu, G. Fiskum, and D. Schubert, "Generation of reactive oxygen species by the mitochondrial electron transport chain," Journal of Neurochemistry, vol. 80, no. 5, pp. 780-787, 2002. 
[61] Q. Chen, E. J. Vazquez, S. Moghaddas, C. L. Hoppel, and E. J. Lesnefsky, "Production of reactive oxygen species by mitochondria: central role of complex III," The Journal of Biological Chemistry, vol. 278, no. 38, pp. 36027-36031, 2003.

[62] V. Adam-Vizi and C. Chinopoulos, "Bioenergetics and the formation of mitochondrial reactive oxygen species," Trends in Pharmacological Sciences, vol. 27, no. 12, pp. 639-645, 2006.

[63] S. Orrenius, "Reactive oxygen species in mitochondriamediated cell death," Drug Metabolism Reviews, vol. 39, no. 2-3, pp. 443-455, 2007.

[64] E. B. Tahara, F. D. T. Navarete, and A. J. Kowaltowski, "Tissue-, substrate-, and site-specific characteristics of mitochondrial reactive oxygen species generation," Free Radical Biology \& Medicine, vol. 46, no. 9, pp. 1283-1297, 2009.

[65] A. J. Lambert and M. D. Brand, "Reactive oxygen species production by mitochondria," Methods in Molecular Biology, vol. 554, pp. 165-181, 2009.

[66] M. P. Murphy, "How mitochondria produce reactive oxygen species," The Biochemical Journal, vol. 417, no. 1, pp. 1-13, 2009.

[67] D. F. Stowe and A. K. Camara, "Mitochondrial reactive oxygen species production in excitable cells: modulators of mitochondrial and cell function," Antioxidants \& Redox Signaling, vol. 11, no. 6, pp. 1373-1414, 2009.

[68] T. Finkel, "Signal transduction by mitochondrial oxidants," The Journal of Biological Chemistry, vol. 287, no. 7, pp. 4434-4440, 2012.

[69] V. G. Grivennikova and A. D. Vinogradov, "Mitochondrial production of reactive oxygen species," Biochemistry, vol. 78, no. 13, pp. 1490-1511, 2013.

[70] D. B. Zorov, M. Juhaszova, and S. J. Sollott, "Mitochondrial reactive oxygen species (ROS) and ROS-induced ROS release," Physiological Reviews, vol. 94, no. 3, pp. 909-950, 2014.

[71] Y. R. Chen and J. L. Zweier, "Cardiac mitochondria and reactive oxygen species generation," Circulation Research, vol. 114, no. 3, pp. 524-537, 2014.

[72] M. Forkink, J. A. M. Smeitink, R. Brock, P. H. G. M. Willems, and W. J. H. Koopman, "Detection and manipulation of mitochondrial reactive oxygen species in mammalian cells," Biochimica et Biophysica Acta (BBA)-Bioenergetics, vol. 1797, no. 6-7, pp. 1034-1044, 2010.

[73] N. Kaludercic, J. Mialet-Perez, N. Paolocci, A. Parini, and F. Di Lisa, "Monoamine oxidases as sources of oxidants in the heart," Journal of Molecular and Cellular Cardiology, vol. 73, pp. 34-42, 2014.

[74] P. H. G. M. Willems, R. Rossignol, C. E. J. Dieteren, M. P. Murphy, and W. J. H. Koopman, "Redox homeostasis and mitochondrial dynamics," Cell Metabolism, vol. 22, no. 2, pp. 207-218, 2015.

[75] J. F. Turrens and A. Boveris, "Generation of superoxide anion by the NADH dehydrogenase of bovine heart mitochondria," The Biochemical Journal, vol. 191, no. 2, pp. 421-427, 1980.

[76] L. Kussmaul and J. Hirst, "The mechanism of superoxide production by NADH:ubiquinone oxidoreductase (complex I) from bovine heart mitochondria," Proceedings of the National Academy of Sciences of the United States of America, vol. 103, no. 20, pp. 7607-7612, 2006.

[77] S. T. Ohnishi, K. Shinzawa-Itoh, K. Ohta, S. Yoshikawa, and T. Ohnishi, "New insights into the superoxide generation sites in bovine heart NADH-ubiquinone oxidoreductase (Complex I): the significance of protein-associated ubiquinone and the dynamic shifting of generation sites between semiflavin and semiquinone radicals," Biochimica et Biophysica Acta, vol. 1797, no. 12, pp. 1901-1909, 2010.

[78] M. L. Genova, B. Ventura, G. Giuliano et al., "The site of production of superoxide radical in mitochondrial Complex I is not a bound ubisemiquinone but presumably iron-sulfur cluster N2," FEBS Letters, vol. 505, no. 3, pp. 364-368, 2001.

[79] P. T. Kang, L. Zhang, C. L. Chen, J. Chen, K. B. Green, and Y. R. Chen, "Protein thiyl radical mediates S-glutathionylation of complex I," Free Radical Biology and Medicine, vol. 53, no. 4, pp. 962-973, 2012.

[80] J. Chen, C.-L. Chen, S. Rawale et al., "Peptide-based antibodies against glutathione-binding domains suppress superoxide production mediated by mitochondrial complex," The Journal of Biological Chemistry, vol. 285, no. 5, pp. 3168-3180, 2010.

[81] C.-L. Chen, L. Zhang, A. Yeh et al., "Site-specific Sglutathiolation of mitochondrial NADH ubiquinone reductase," Biochemistry, vol. 46, no. 19, pp. 5754-5765, 2007.

[82] Y.-R. Chen, C.-L. Chen, L. Zhang, K. B. Green-Church, and J. L. Zweier, "Superoxide generation from mitochondrial NADH dehydrogenase induces self-inactivation with specific protein radical formation," The Journal of Biological Chemistry, vol. 280, no. 45, pp. 37339-37348, 2005.

[83] K. R. Pryde and J. Hirst, "Superoxide is produced by the reduced flavin in mitochondrial complex I: a single, unified mechanism that applies during both forward and reverse electron transfer," The Journal of Biological Chemistry, vol. 286, no. 20, pp. $18056-$ 18065, 2011.

[84] J. St-Pierre, J. A. Buckingham, S. J. Roebuck, and M. D. Brand, "Topology of superoxide production from different sites in the mitochondrial electron transport chain," The Journal of Biological Chemistry, vol. 277, no. 47, pp. 44784-44790, 2002.

[85] S. T. Ohnishi, T. Ohnishi, S. Muranaka et al., "A possible site of superoxide generation in the complex I segment of rat heart mitochondria," Journal of Bioenergetics and Biomembranes, vol. 37, no. 1, pp. 1-15, 2005.

[86] Y. Kushnareva, A. N. Murphy, and A. Andreyev, "Complex Imediated reactive oxygen species generation: modulation by cytochrome $\mathrm{c}$ and $\mathrm{NAD}(\mathrm{P})+$ oxidation-reduction state," The Biochemical Journal, vol. 368, no. 2, pp. 545-553, 2002.

[87] A. P. Kudin, N. Y.-B. Bimpong-Buta, S. Vielhaber, C. E. Elger, and W. S. Kunz, "Characterization of superoxide-producing sites in isolated brain mitochondria," The Journal of Biological Chemistry, vol. 279, no. 6, pp. 4127-4135, 2004.

[88] J. F. Turrens, B. A. Freeman, J. G. Levitt, and J. D. Crapo, “The effect of hyperoxia on superoxide production by lung submitochondrial particles," Archives of Biochemistry and Biophysics, vol. 217, no. 2, pp. 401-410, 1982.

[89] A. J. Lambert and M. D. Brand, "Superoxide production by NADH:ubiquinone oxidoreductase (complex I) depends on the $\mathrm{pH}$ gradient across the mitochondrial inner membrane," Biochemical Journal, vol. 382, no. 2, pp. 511-517, 2004.

[90] A. J. Lambert and M. D. Brand, "Inhibitors of the quinonebinding site allow rapid superoxide production from mitochondrial NADH:ubiquinone oxidoreductase (complex I)," The Journal of Biological Chemistry, vol. 279, no. 38, pp. 3941439420, 2004.

[91] J. R. Treberg, C. L. Quinlan, and M. D. Brand, "Evidence for two sites of superoxide production by mitochondrial NADHubiquinone oxidoreductase (complex I)," The Journal of Biological Chemistry, vol. 286, no. 31, pp. 27103-27110, 2011.

[92] Y.-R. Chen, C.-L. Chen, D. R. Pfeiffer, and J. L. Zweier, "Mitochondrial complex II in the post-ischemic heart: oxidative 
injury and the role of protein S-glutathionylation," The Journal of Biological Chemistry, vol. 282, no. 45, pp. 32640-32654, 2007.

[93] R. G. Hansford, B. A. Hogue, and V. Mildaziene, "Dependence of $\mathrm{H}_{2} \mathrm{O}_{2}$ formation by rat heart mitochondria on substrate availability and donor age," Journal of Bioenergetics and Biomembranes, vol. 29, no. 1, pp. 89-95, 1997.

[94] I. Siebels and S. Dröse, "Q-site inhibitor induced ROS production of mitochondrial complex II is attenuated by TCA cycle dicarboxylates," Biochimica et Biophysica Acta (BBA)Bioenergetics, vol. 1827, no. 10, pp. 1156-1164, 2013.

[95] Y.-R. Chen, C.-L. Chen, A. Yeh, X. Liu, and J. L. Zweier, "Direct and indirect roles of cytochrome b in the mediation of superoxide generation and $\mathrm{NO}$ catabolism by mitochondrial succinate-cytochrome c reductase," The Journal of Biological Chemistry, vol. 281, no. 19, pp. 13159-13168, 2006.

[96] L. Zhang, L. Yu, and C.-A. Yu, "Generation of superoxide anion by succinate-cytochrome $\mathrm{c}$ reductase from bovine heart mitochondria," Journal of Biological Chemistry, vol. 273, no. 51, pp. 33972-33976, 1998.

[97] T. V. Votyakova and I. J. Reynolds, “DeltaPsi(m)-dependent and -independent production of reactive oxygen species by rat brain mitochondria," Journal of Neurochemistry, vol. 79, no. 2, pp. 266-277, 2001.

[98] C. L. Quinlan, A. L. Orr, I. V. Perevoshchikova, J. R. Treberg, B. A. Ackrell, and M. D. Brand, "Mitochondrial complex II can generate reactive oxygen species at high rates in both the forward and reverse reactions," The Journal of Biological Chemistry, vol. 287, no. 32, pp. 27255-27264, 2012.

[99] J. Guo and B. D. Lemire, "The ubiquinone-binding site of the Saccharomyces cerevisiae succinate-ubiquinone oxidoreductase is a source of superoxide," The Journal of Biological Chemistry, vol. 278, no. 48, pp. 47629-47635, 2003.

[100] V. Yankovskaya, R. Horsefield, S. Törnroth et al., "Architecture of succinate dehydrogenase and reactive oxygen species generation," Science, vol. 299, no. 5607, pp. 700-704, 2003.

[101] A. Boveris, E. Cadenas, and A. O. M. Stoppani, "Role of ubiquinone in the mitochondrial generation of hydrogen peroxide," Biochemical Journal, vol. 156, no. 2, pp. 435-444, 1976.

[102] E. Cadenas, A. Boveris, C. I. Ragan, and A. O. M. Stoppani, "Production of superoxide radicals and hydrogen peroxide by NADH-ubiquinone reductase and ubiquinol-cytochrome $\mathrm{c}$ reductase from beef-heart mitochondria," Archives of Biochemistry and Biophysics, vol. 180, no. 2, pp. 248-257, 1977.

[103] J. F. Turrens, A. Alexandre, and A. L. Lehninger, "Ubisemiquinone is the electron donor for superoxide formation by complex III of heart mitochondria," Archives of Biochemistry and Biophysics, vol. 237, no. 2, pp. 408-414, 1985.

[104] A. A. Starkov and G. Fiskum, "Myxothiazol induces $\mathrm{H}_{2} \mathrm{O}_{2}$ production from mitochondrial respiratory chain," Biochemical and Biophysical Research Communications, vol. 281, no. 3, pp. 645-650, 2001.

[105] D. Han, E. Williams, and E. Cadenas, "Mitochondrial respiratory chain-dependent generation of superoxide anion and its release into the intermembrane space," The Biochemical Journal, vol. 353, no. 2, pp. 411-416, 2001.

[106] F. L. Muller, Y. Liu, and H. Van Remmen, "Complex III releases superoxide to both sides of the inner mitochondrial membrane," The Journal of Biological Chemistry, vol. 279, no. 47, pp. 4906449073, 2004.

[107] J. L. Cape, M. K. Bowman, and D. M. Kramer, "A semiquinone intermediate generated at the Qo site of the cytochrome bcl complex: importance for the Q-cycle and superoxide production," Proceedings of the National Academy of Sciences of the United States of America, vol. 104, no. 19, pp. 7887-7892, 2007.

[108] S. K. Prabu, H. K. Anandatheerthavarada, H. Raza, S. Srinivasan, J. F. Spear, and N. G. Avadhani, "Protein kinase Amediated phosphorylation modulates cytochrome $\mathrm{c}$ oxidase function and augments hypoxia and myocardial ischemiarelated injury," The Journal of Biological Chemistry, vol. 281, no. 4, pp. 2061-2070, 2006.

[109] L. K. Kwong and R. S. Sohal, "Substrate and site specificity of hydrogen peroxide generation in mouse Mitochondria," Archives of Biochemistry and Biophysics, vol. 350, no. 1, pp. 118126, 1998.

[110] Z. Drahota, S. K. R. Chowdhury, D. Floryk et al., "Glycerophosphate-dependent hydrogen peroxide production by brown adipose tissue mitochondria and its activation by ferricyanide," Journal of Bioenergetics and Biomembranes, vol. 34, no. 2, pp. 105-113, 2002.

[111] S. Miwa, J. St-Pierre, L. Partridge, and M. D. Brand, "Superoxide and hydrogen peroxide production by Drosophila mitochondria," Free Radical Biology and Medicine, vol. 35, no. 8, pp. 938948, 2003.

[112] H. J. Forman and J. Kennedy, "Dihydroorotate-dependent superoxide producton in rat brain and liver: a function of the primary dehydrogenase," Archives of Biochemistry and Biophysics, vol. 173, no. 1, pp. 219-224, 1976.

[113] M. Hey-Mogensen, R. L. S. Goncalves, A. L. Orr, and M. D. Brand, "Production of superoxide $/ \mathrm{H}_{2} \mathrm{O}_{2}$ by dihydroorotate dehydrogenase in rat skeletal muscle mitochondria," Free Radical Biology and Medicine, vol. 72, pp. 149-155, 2014.

[114] M. Löffler, C. Becker, E. Wegerle, and G. Schuster, "Catalytic enzyme histochemistry and biochemical analysis of dihydroorotate dehydrogenase/oxidase and succinate dehydrogenase in mammalian tissues, cells and mitochondria," Histochemistry and Cell Biology, vol. 105, no. 2, pp. 119-128, 1996.

[115] N. Hail, P. Chen, J. J. Kepa, L. R. Bushman, and C. Shearn, "Dihydroorotate dehydrogenase is required for $\mathrm{N}$ (4-hydroxyphenyl)retinamide-induced reactive oxygen species production and apoptosis," Free Radical Biology and Medicine, vol. 49, no. 1, pp. 109-116, 2010.

[116] M. Giorgio, E. Migliaccio, F. Orsini et al., "Electron transfer between cytochrome $\mathrm{c}$ and p66Shc generates reactive oxygen species that trigger mitochondrial apoptosis," Cell, vol. 122, no. 2, pp. 221-233, 2005.

[117] G. G. Camici, M. Schiavoni, P. Francia et al., "Genetic deletion of p66Shc adaptor protein prevents hyperglycemia-induced endothelial dysfunction and oxidative stress," Proceedings of the National Academy of Sciences of the United States of America, vol. 104, no. 12, pp. 5217-5222, 2007.

[118] J. Vásquez-Vivar, B. Kalyanaraman, and M. C. Kennedy, "Mitochondrial aconitase is a source of hydroxyl radical. An electron spin resonance investigation," The Journal of Biological Chemistry, vol. 275, no. 19, pp. 14064-14069, 2000.

[119] L. Tretter and V. Adam-Vizi, "Generation of reactive oxygen species in the reaction catalyzed by $\alpha$-ketoglutarate dehydrogenase," The Journal of Neuroscience, vol. 24, no. 36, pp. 7771-7778, 2004.

[120] A. A. Starkov, G. Fiskum, C. Chinopoulos et al., "Mitochondrial $\alpha$-ketoglutarate dehydrogenase complex generates reactive oxygen species," The Journal of Neuroscience, vol. 24, no. 36, pp. 7779-7788, 2004. 
[121] S. A. Whatley, D. Curti, F. Das Gupta et al., "Superoxide, neuroleptics and the ubiquinone and cytochrome b5 reductases in brain and lymphocytes from normals and schizophrenic patients," Molecular Psychiatry, vol. 3, no. 3, pp. 227-237, 1998.

[122] N. Hauptmann, J. Grimsby, J. C. Shih, and E. Cadenas, "The metabolism of tyramine by monoamine oxidase A/B causes oxidative damage to mitochondrial DNA," Archives of Biochemistry and Biophysics, vol. 335, no. 2, pp. 295-304, 1996.

[123] A. Maurel, C. Hernandez, O. Kunduzova et al., "Agedependent increase in hydrogen peroxide production by cardiac monoamine oxidase A in rats," American Journal of Physiology-Heart and Circulatory Physiology, vol. 284, no. 4, pp. H1460-H1467, 2003.

[124] F. Carvalho, J. A. Duarte, M. J. Neuparth et al., "Hydrogen peroxide production in mouse tissues after acute $d$-amphetamine administration. Influence of monoamine oxidase inhibition," Archives of Toxicology, vol. 75, no. 8, pp. 465-469, 2001.

[125] C. Villeneuve, C. Guilbeau-Frugier, P. Sicard et al., "P53PGC- $1 \alpha$ pathway mediates oxidative mitochondrial damage and cardiomyocyte necrosis induced by monoamine oxidasea upregulation: role in chronic left ventricular dysfunction in mice," Antioxidants \& Redox Signaling, vol. 18, no. 1, pp. 5-18, 2013.

[126] N. Kaludercic, A. Carpi, T. Nagayama et al., "Monoamine Oxidase B prompts mitochondrial and cardiac dysfunction in pressure overloaded hearts," Antioxidants and Redox Signaling, vol. 20, no. 2, pp. 267-280, 2014.

[127] A. Sturza, M. S. Leisegang, A. Babelova et al., "Monoamine oxidases are mediators of endothelial dysfunction in the mouse aorta," Hypertension, vol. 62, no. 1, pp. 140-146, 2013.

[128] A. Sturza, O. M. Duicu, A. Vaduva et al., "Monoamine oxidases are novel sources of cardiovascular oxidative stress in experimental diabetes," Canadian Journal of Physiology and Pharmacology, vol. 93, no. 7, pp. 555-561, 2015.

[129] M. J. Kumar, D. G. Nicholls, and J. K. Andersen, "Oxidative $\alpha$ ketoglutarate dehydrogenase inhibition via subtle elevations in monoamine oxidase B levels results in loss of spare respiratory capacity: implications for Parkinson's disease," The Journal of Biological Chemistry, vol. 278, no. 47, pp. 46432-46439, 2003.

[130] E. J. Anderson, J. T. Efird, S. W. Davies et al., "Monoamine oxidase is a major determinant of redox balance in human atrial myocardium and is associated with postoperative atrial fibrillation," Journal of the American Heart Association, vol. 3, no. 1, Article ID e000713, 2014.

[131] K.-U. Lee, I. K. Lee, J. Han et al., "Effects of recombinant adenovirus-mediated uncoupling protein 2 overexpression on endothelial function and apoptosis," Circulation Research, vol. 96, no. 11, pp. 1200-1207, 2005.

[132] Y. Teshima, M. Akao, S. P. Jones, and E. Marbán, “Uncoupling protein-2 overexpression inhibits mitochondrial death pathway in cardiomyocytes," Circulation Research, vol. 93, no. 3, pp. 192200, 2003.

[133] F. Valsecchi, S. Grefte, P. Roestenberg et al., "Primary fibroblasts of NDUFS4-/- mice display increased ROS levels and aberrant mitochondrial morphology," Mitochondrion, vol. 13, no. 5, pp. 436-443, 2013.

[134] L. Blanchet, S. Grefte, J. A. M. Smeitink, P. H. G. M. Willems, and W. J. H. Koopman, "Photo-induction and automated quantification of reversible mitochondrial permeability transition pore opening in primary mouse myotubes," PLoS ONE, vol. 9, no. 11, Article ID el14090, 2014.
[135] C. Brenner and M. Moulin, "Physiological roles of the permeability transition pore," Circulation Research, vol. 111, no. 9, pp. 1237-1247, 2012.

[136] F. Ichas and J.-P. Mazat, "From calcium signaling to cell death: two conformations for the mitochondrial permeability transition pore. Switching from low- to high-conductance state," Biochimica et Biophysica Acta, vol. 1366, no. 1-2, pp. 33-50, 1998.

[137] L. Sun, S. Shukair, T. J. Naik, F. Moazed, and H. Ardehali, "Glucose phosphorylation and mitochondrial binding are required for the protective effects of hexokinases I and II," Molecular and Cellular Biology, vol. 28, no. 3, pp. 1007-1017, 2008.

[138] C.-L. Chen, J. Chen, S. Rawale et al., "Protein tyrosine nitration of the flavin subunit is associated with oxidative modification of mitochondrial complex II in the post-ischemic myocardium," Journal of Biological Chemistry, vol. 283, no. 41, pp. 2799128003, 2008.

[139] J. Garcia, D. Han, H. Sancheti, L.-P. Yap, N. Kaplowitz, and E. Cadenas, "Regulation of mitochondrial glutathione redox status and protein glutathionylation by respiratory substrates," Journal of Biological Chemistry, vol. 285, no. 51, pp. 39646-39654, 2010.

[140] S. M. Beer, E. R. Taylor, S. E. Brown et al., "Glutaredoxin 2 catalyzes the reversible oxidation and glutathionylation of mitochondrial membrane thiol proteins: implications for mitochondrial redox regulation and antioxidant defense," Journal of Biological Chemistry, vol. 279, no. 46, pp. 47939-47951, 2004.

[141] T. R. Hurd, R. Requejo, A. Filipovska et al., "Complex I within oxidatively stressed bovine heart mitochondria is glutathionylated on Cys-531 and Cys-704 of the $75-\mathrm{kDa}$ subunit: potential role of Cys residues in decreasing oxidative damage," The Journal of Biological Chemistry, vol. 283, no. 36, pp. 24801-24815, 2008.

[142] E. R. Taylor, F. Hurrell, R. J. Shannon, T.-K. Lin, J. Hirst, and M. P. Murphy, "Reversible glutathionylation of complex I increases mitochondrial superoxide formation," Journal of Biological Chemistry, vol. 278, no. 22, pp. 19603-19610, 2003.

[143] D. C. Liemburg-Apers, P. H. G. M. Willems, W. J. H. Koopman, and S. Grefte, "Interactions between mitochondrial reactive oxygen species and cellular glucose metabolism," Archives of Toxicology, vol. 89, no. 8, pp. 1209-1226, 2015.

[144] K. A. Brand and U. Hermfisse, "Aerobic glycolysis by proliferating cells: a protective strategy against reactive oxygen species," The FASEB Journal, vol. 11, no. 5, pp. 388-395, 1997.

[145] G. Debska, A. Kicinska, J. Skalska et al., "Opening of potassium channels modulates mitochondrial function in rat skeletal muscle," Biochimica et Biophysica Acta, vol. 1556, no. 2-3, pp. 97105, 2002.

[146] A. Petruş, O. M. Duicu, A. Sturza et al., "Modulation of mitochondrial respiratory function and ROS production by novel benzopyran analogues," Canadian Journal of Physiology and Pharmacology, vol. 93, no. 9, pp. 811-818, 2015.

[147] P. P. Dzeja, P. Bast, C. Ozcan et al., "Targeting nucleotiderequiring enzymes: implications for diazoxide-induced cardioprotection," American Journal of Physiology-Heart and Circulatory Physiology, vol. 284, no. 4, pp. H1048-H1056, 2003.

[148] T. R. Cung, O. Morel, G. Cayla et al., "Cyclosporine before PCI in patients with acute myocardial infarction," The New England Journal of Medicine, vol. 373, no. 11, pp. 1021-1031, 2015.

[149] D. Atar, H. Arheden, A. Berdeaux et al., "Effect of intravenous TRO40303 as an adjunct to primary percutaneous coronary intervention for acute ST-elevation myocardial infarction: MITOCARE study results," European Heart Journal, vol. 36, no. 2, pp. 112-119, 2015. 
[150] C. M. Gibson, R. P. Giugliano, R. A. Kloner et al., "EMBRACE STEMI study: a phase $2 \mathrm{a}$ trial to evaluate the safety, tolerability, and efficacy of intravenous MTP-131 on reperfusion injury in patients undergoing primary percutaneous coronary intervention," European Heart Journal, 2015.

[151] D. A. Jones, C. Pellaton, S. Velmurugan et al., "Randomized phase 2 trial of intracoronary nitrite during acute myocardial infarction," Circulation Research, vol. 116, no. 3, pp. 437-447, 2015.

[152] N. Siddiqi, C. Neil, M. Bruce et al., "Intravenous sodium nitrite in acute ST-elevation myocardial infarction: a randomized controlled trial (NIAMI)," European Heart Journal, vol. 35, no. 19, pp. 1255-1262, 2014.

[153] M. Forkink, F. Basit, J. Teixeira, H. G. Swarts, W. J. H. Koopman, and P. H. G. M. Willems, "Complex I and complex III inhibition specifically increase cytosolic hydrogen peroxide levels without inducing oxidative stress in HEK293 cells," Redox Biology, vol. 6, pp. 607-616, 2015.

[154] J. R. Burgoyne, H. Mongue-Din, P. Eaton, and A. M. Shah, "Redox signaling in cardiac physiology and pathology," Circulation Research, vol. 111, no. 8, pp. 1091-1106, 2012.

[155] S. F. Steinberg, "Oxidative stress and sarcomeric proteins," Circulation Research, vol. 112, no. 2, pp. 393-405, 2013.

[156] D. B. Zorov, C. R. Filburn, L.-O. Klotz, J. L. Zweier, and S. J. Sollott, "Reactive oxygen species (ROS)-induced ROS release: a new phenomenon accompanying induction of the mitochondrial permeability transition in cardiac myocytes," The Journal of Experimental Medicine, vol. 192, no. 7, pp. 1001-1014, 2000.

[157] A. Daiber, "Redox signaling (cross-talk) from and to mitochondria involves mitochondrial pores and reactive oxygen species," Biochimica et Biophysica Acta (BBA)-Bioenergetics, vol. 1797, no. 6-7, pp. 897-906, 2010.

[158] S. Karbach, P. Wenzel, A. Waisman, T. Münzel, and A. Daiber, "eNOS uncoupling in cardiovascular diseases-the role of oxidative stress and inflammation," Current Pharmaceutical Design, vol. 20, no. 22, pp. 3579-3594, 2014.

[159] J.-M. Li and A. M. Shah, "Endothelial cell superoxide generation: regulation and relevance for cardiovascular pathophysiology," American Journal of Physiology-Regulatory Integrative and Comparative Physiology, vol. 287, no. 5, pp. R1014-R1030, 2004.

[160] Y. Liu, H. Zhao, H. Li, B. Kalyanaraman, A. C. Nicolosi, and D. D. Gutterman, "Mitochondrial sources of $\mathrm{H}_{2} \mathrm{O}_{2}$ generation play a key role in flow-mediated dilation in human coronary resistance arteries," Circulation Research, vol. 93, no. 6, pp. 573580, 2003.

[161] D. X. Zhang, L. Borbouse, D. Gebremedhin et al., " $\mathrm{H}_{2} \mathrm{O}_{2}$ induced dilation in human coronary arterioles: role of protein kinase $\mathrm{G}$ dimerization and large-conductance $\mathrm{Ca}^{2+}$-activated $\mathrm{K}^{+}$channel activation," Circulation Research, vol. 110, no. 3, pp. 471-480, 2012.

[162] Y. F. Pung, W. J. Sam, K. Stevanov et al., "Mitochondrial oxidative stress corrupts coronary collateral growth by activating adenosine monophosphate activated kinase- $\alpha$ signaling," Arteriosclerosis, Thrombosis, and Vascular Biology, vol. 33, no. 8, pp. 1911-1919, 2013.

[163] S.-I. Saitoh, T. Kiyooka, P. Rocic et al., "Redox-dependent coronary metabolic dilation," American Journal of PhysiologyHeart and Circulatory Physiology, vol. 293, no. 6, pp. H3720H3725, 2007.
[164] P. A. Rogers, W. M. Chilian, I. N. Bratz, R. M. Bryan Jr., and G. M. Dick, " $\mathrm{H}_{2} \mathrm{O}_{2}$ activates redox- and 4-aminopyridine-sensitive $\mathrm{Kv}$ channels in coronary vascular smooth muscle," American Journal of Physiology-Heart and Circulatory Physiology, vol. 292, no. 3, pp. H1404-H1411, 2007.

[165] R. D. Guzy and P. T. Schumacker, "Oxygen sensing by mitochondria at complex III: the paradox of increased reactive oxygen species during hypoxia," Experimental Physiology, vol. 91, no. 5, pp. 807-819, 2006.

[166] B. Liu, A. K. Tewari, L. Zhang et al., "Proteomic analysis of protein tyrosine nitration after ischemia reperfusion injury: mitochondria as the major target," Biochimica et Biophysica Acta-Proteins and Proteomics, vol. 1794, no. 3, pp. 476-485, 2009.

[167] J. F. Spear, S. K. Prabu, D. Galati, H. Raza, H. K. Anandatheerthavarada, and N. G. Avadhani, " $\beta_{1}$-Adrenoreceptor activation contributes to ischemia-reperfusion damage as well as playing a role in ischemic preconditioning," American Journal of Physiology-Heart and Circulatory Physiology, vol. 292, no. 5, pp. H2459-H2466, 2007.

[168] H.-L. Lee, C.-L. Chen, S. T. Yeh, J. L. Zweier, and Y.-R. Chen, "Biphasic modulation of the mitochondrial electron transport chain in myocardial ischemia and reperfusion," American Journal of Physiology-Heart and Circulatory Physiology, vol. 302, no. 7, pp. H1410-H1422, 2012.

[169] G. Paradies, G. Petrosillo, M. Pistolese, N. Di Venosa, A. Federici, and F. M. Ruggiero, "Decrease in mitochondrial complex I activity in ischemic/reperfused rat heart: involvement of reactive oxygen species and cardiolipin," Circulation Research, vol. 94, no. 1, pp. 53-59, 2004.

[170] A. K. Gadicherla, D. F. Stowe, W. E. Antholine, M. Yang, and A. K. S. Camara, "Damage to mitochondrial complex i during cardiac ischemia reperfusion injury is reduced indirectly by anti-anginal drug ranolazine," Biochimica et Biophysica Acta (BBA)-Bioenergetics, vol. 1817, no. 3, pp. 419-429, 2012.

[171] J. L. Zweier, J. T. Flaherty, and M. L. Weisfeldt, "Direct measurement of free radical generation following reperfusion of ischemic myocardium," Proceedings of the National Academy of Sciences of the United States of America, vol. 84, no. 5, pp. 14041407, 1987.

[172] G. Petrosillo, F. M. Ruggiero, N. Di Venosa, and G. Paradies, "Decreased complex III activity in mitochondria isolated from rat heart subjected to ischemia and reperfusion: role of reactive oxygen species and cardiolipin," The FASEB Journal, vol. 17, no. 6, pp. 714-716, 2003.

[173] S. Dröse, P. J. Hanley, and U. Brandt, "Ambivalent effects of diazoxide on mitochondrial ROS production at respiratory chain complexes I and III," Biochimica et Biophysica Acta (BBA)_General Subjects, vol. 1790, no. 6, pp. 558-565, 2009.

[174] P. Bianchi, O. Kunduzova, E. Masini et al., "Oxidative stress by monoamine oxidase mediates receptor-independent cardiomyocyte apoptosis by serotonin and postischemic myocardial injury," Circulation, vol. 112, no. 21, pp. 3297-3305, 2005.

[175] N. Kaludercic, A. Carpi, R. Menabò, F. Di Lisa, and N. Paolocci, "Monoamine oxidases (MAO) in the pathogenesis of heart failure and ischemia/reperfusion injury," Biochimica et Biophysica Acta, vol. 1813, no. 7, pp. 1323-1332, 2011.

[176] P. Bianchi, D. R. Pimentel, M. P. Murphy, W. S. Colucci, and A. Parini, "A new hypertrophic mechanism of serotonin in cardiac myocytes: receptor-independent ROS generation," The FASEB Journal, vol. 19, no. 6, pp. 641-643, 2005. 
[177] A. Carpi, R. Menabò, N. Kaludercic, P. Pelicci, F. Di Lisa, and M. Giorgio, "The cardioprotective effects elicited by p66Shc ablation demonstrate the crucial role of mitochondrial ROS formation in ischemia/reperfusion injury," Biochimica et Biophysica Acta, vol. 1787, no. 7, pp. 774-780, 2009.

[178] N. Kaludercic, E. Takimoto, T. Nagayama et al., "Monoamine oxidase a-mediated enhanced catabolism of norepinephrine contributes to adverse remodeling and pump failure in hearts with pressure overload," Circulation Research, vol. 106, no. 1, pp. 193-202, 2010.

[179] S. D. Sivasubramaniam, C. C. Finch, M. J. Rodriguez, N. Mahy, and E. E. Billett, "A comparative study of the expression of monoamine oxidase-A and -B mRNA and protein in non-CNS human tissues," Cell and Tissue Research, vol. 313, no. 3, pp. 291300, 2003.

[180] R. Vogel, H. Wiesinger, B. Hamprecht, and R. Dringen, "The regeneration of reduced glutathione in rat forebrain mitochondria identifies metabolic pathways providing the NADPH required," Neuroscience Letters, vol. 275, no. 2, pp. 97-100, 1999.

[181] I. Andreadou, E. K. Iliodromitis, D. Farmakis, and D. T. Kremastinos, "To prevent, protect and save the ischemic heart: antioxidants revisited," Expert Opinion on Therapeutic Targets, vol. 13, no. 8, pp. 945-956, 2009.

[182] P. M. W. Bath, L. J. Gray, A. J. G. Bath, A. Buchan, T. Miyata, and A. R. Green, "Effects of NXY-059 in experimental stroke: an individual animal meta-analysis," British Journal of Pharmacology, vol. 157, no. 7, pp. 1157-1171, 2009.

[183] T. Jaxa-Chamiec, B. Bednarz, K. Herbaczynska-Cedro, P. Maciejewski, and L. Ceremuzynski, "Effects of vitamins $C$ and $\mathrm{E}$ on the outcome after acute myocardial infarction in diabetics: a retrospective, hypothesis-generating analysis from the MIVIT Study," Cardiology, vol. 112, no. 3, pp. 219-223, 2009.

[184] D. P. Vivekananthan, M. S. Penn, S. K. Sapp, A. Hsu, and E. J. Topol, "Use of antioxidant vitamins for the prevention of cardiovascular disease: meta-analysis of randomised trials," The Lancet, vol. 361, no. 9374, pp. 2017-2023, 2003.

[185] S. R. Steinhubl, "Why have antioxidants failed in clinical trials?" The American Journal of Cardiology A, vol. 101, no. 10, pp. S14S19, 2008.

[186] A. Dhanasekaran, S. Kotamraju, S. V. Kalivendi et al., "Supplementation of endothelial cells with mitochondria-targeted antioxidants inhibit peroxide-induced mitochondrial iron uptake, oxidative damage, and apoptosis," The Journal of Biological Chemistry, vol. 279, no. 36, pp. 37575-37587, 2004.

[187] M. V. Covey, M. P. Murphy, C. E. Hobbs, R. A. J. Smith, and D. E. Oorschot, "Effect of the mitochondrial antioxidant, Mito Vitamin E, on hypoxic-ischemic striatal injury in neonatal rats: a dose-response and stereological study," Experimental Neurology, vol. 199, no. 2, pp. 513-519, 2006.

[188] S. M. Davidson and M. R. Duchen, "Endothelial mitochondria: contributing to vascular function and disease," Circulation Research, vol. 100, no. 8, pp. 1128-1141, 2007.

[189] V. J. Adlam, J. C. Harrison, C. M. Porteous et al., "Targeting an antioxidant to mitochondria decreases cardiac ischemiareperfusion injury," The FASEB Journal, vol. 19, no. 9, pp. 10881095, 2005.

[190] L. E. Bakeeva, I. V. Barskov, M. V. Egorov et al., "Mitochondriatargeted plastoquinone derivatives as tools to interrupt execution of the aging program. 2. Treatment of some ROS- and agerelated diseases (heart arrhythmia, heart infarctions, kidney ischemia, and stroke)," Biochemistry, vol. 73, no. 12, pp. 12881299, 2008.
[191] J. Navarro-Yepes, L. Zavala-Flores, A. Anandhan et al., "Antioxidant gene therapy against neuronal cell death," Pharmacology and Therapeutics, vol. 142, no. 2, pp. 206-230, 2014.

[192] Y.-B. Ouyang, C. M. Stary, R. E. White, and R. G. Giffard, "The use of microRNAs to modulate redox and immune response to stroke," Antioxidants \& Redox Signaling, vol. 22, no. 2, pp. 187202, 2015.

[193] D. J. Hearse, S. M. Humphrey, and E. B. Chain, "Abrupt reoxygenation of the anoxic potassium-arrested perfused rat heart: a study of myocardial enzyme release," Journal of Molecular and Cellular Cardiology, vol. 5, no. 4, pp. 395-407, 1973.

[194] K. A. Reimer, C. E. Murry, and V. J. Richard, "The role of neutrophils and free radicals in the ischemic-reperfused heart: why the confusion and controversy?" Journal of Molecular and Cellular Cardiology, vol. 21, no. 12, pp. 1225-1239, 1989.

[195] C. E. Murry, R. B. Jennings, and K. A. Reimer, "Preconditioning with ischemia: a delay of lethal cell injury in ischemic myocardium," Circulation, vol. 74, no. 5, pp. 1124-1136, 1986.

[196] Z. Q. Zhao, J. S. Corvera, M. E. Halkos et al., "Inhibition of myocardial injury by ischemic postconditioning during reperfusion: comparison with ischemic preconditioning," American Journal of Physiology Heart and Circulatory Physiology, vol. 285, no. 2, pp. H579-H588, 2003.

[197] G. Heusch, "Postconditioning: old wine in a new bottle?" Journal of the American College of Cardiology, vol. 44, no. 5, pp. 1111-1112, 2004.

[198] S. Y. Lim and D. J. Hausenloy, "Remote ischemic conditioning: from bench to bedside," Frontiers in Physiology, vol. 3, article 27, 2012.

[199] M. V. Cohen and J. M. Downey, "Signalling pathways and mechanisms of protection in pre- and postconditioning: historical perspective and lessons for the future," British Journal of Pharmacology, vol. 172, no. 8, pp. 1913-1932, 2015.

[200] G. Heusch, "Molecular basis of cardioprotection: signal transduction in ischemic pre-, post-, and remote conditioning," Circulation Research, vol. 116, no. 4, pp. 674-699, 2015.

[201] T. L. Vanden Hoek, L. B. Becker, Z. Shao, C. Li, and P. T. Schumacker, "Reactive oxygen species released from mitochondria during brief hypoxia induce preconditioning in cardiomyocytes," The Journal of Biological Chemistry, vol. 273, no. 29, pp. 18092-18098, 1998.

[202] R. Quarrie, B. M. Cramer, D. S. Lee et al., "Ischemic preconditioning decreases mitochondrial proton leak and reactive oxygen species production in the postischemic heart," Journal of Surgical Research, vol. 165, no. 1, pp. 5-14, 2011.

[203] I. Tritto, D. D’Andrea, N. Eramo et al., "Oxygen radicals can induce preconditioning in rabbit hearts," Circulation Research, vol. 80, no. 5, pp. 743-748, 1997.

[204] W. Chen, S. Gabel, C. Steenbergen, and E. Murphy, "A redoxbased mechanism for cardioprotection induced by ischemic preconditioning in perfused rat heart," Circulation Research, vol. 77, no. 2, pp. 424-429, 1995.

[205] R. A. Forbes, C. Steenbergen, and E. Murphy, "Diazoxideinduced cardioprotection requires signaling through a redoxsensitive mechanism," Circulation Research, vol. 88, no. 8, pp. 802-809, 2001.

[206] H. Otani, "Reactive oxygen species as mediators of signal transduction in ischemic preconditioning," Antioxidants and Redox Signaling, vol. 6, no. 2, pp. 449-469, 2004.

[207] A. D. T. Costa, R. Jakob, C. L. Costa, K. Andrukhiv, I. C. West, and K. D. Garlid, "The mechanism by which the mitochondrial ATP-sensitive $\mathrm{K}^{+}$channel opening and $\mathrm{H}_{2} \mathrm{O}_{2}$ inhibit the 
mitochondrial permeability transition," The Journal of Biological Chemistry, vol. 281, no. 30, pp. 20801-20808, 2006.

[208] E. Murphy and C. Steenbergen, "Mechanisms underlying acute protection from cardiac ischemia-reperfusion injury," Physiological Reviews, vol. 88, no. 2, pp. 581-609, 2008.

[209] V. Petronilli, D. Penzo, L. Scorrano, P. Bernardi, and F. Di Lisa, "The mitochondrial permeability transition, release of cytochrome $\mathrm{c}$ and cell death. Correlation with the duration of pore openings in situ," The Journal of Biological Chemistry, vol. 276, no. 15, pp. 12030-12034, 2001.

[210] D. J. Hausenloy, S. Y. Lim, S.-G. Ong, S. M. Davidson, and D. M. Yellon, "Mitochondrial cyclophilin-D as a critical mediator of ischaemic preconditioning," Cardiovascular Research, vol. 88, no. 1, pp. 67-74, 2010.

[211] N. Yamashita, S. Hoshida, N. Taniguchi, T. Kuzuya, and M. Hori, "Whole-body hyperthermia provides biphasic cardioprotection against Ischemia/reperfusion injury in the rat," Circulation, vol. 98, no. 14, pp. 1414-1421, 1998.

[212] Y. Yaguchi, H. Satoh, N. Wakahara et al., "Protective effects of hydrogen peroxide against ischemia/reperfusion injury in perfused rat hearts," Circulation Journal, vol. 67, no. 3, pp. 253258, 2003.

[213] C. Penna, D. Mancardi, R. Rastaldo, and P. Pagliaro, "Cardioprotection: a radical view: free radicals in pre and postconditioning," Biochimica et Biophysica Acta (BBA)-Bioenergetics, vol. 1787, no. 7, pp. 781-793, 2009.

[214] M. D. Dănilă, A. I. Privistirescu, S. N. Mirica et al., "Acute inhibition of monoamine oxidase and ischemic preconditioning in isolated rat hearts: interference with postischemic functional recovery but no effect on infarct size reduction," Canadian Journal of Physiology and Pharmacology, vol. 93, no. 9, pp. 819825, 2015.

[215] C. Penna, R. Rastaldo, D. Mancardi et al., "Post-conditioning induced cardioprotection requires signaling through a redoxsensitive mechanism, mitochondrial ATP-sensitive $\mathrm{K}^{+}$channel and protein kinase C activation," Basic Research in Cardiology, vol. 101, no. 2, pp. 180-189, 2006.

[216] Y. M. Tsutsumi, T. Yokoyama, Y. Horikawa, D. M. Roth, and H. H. Patel, "Reactive oxygen species trigger ischemic and pharmacological postconditioning: In vivo and in vitro characterization," Life Sciences, vol. 81, no. 15, pp. 1223-1227, 2007.

[217] P. Sörensson, N. Saleh, F. Bouvier et al., "Effect of postconditioning on infarct size in patients with ST elevation myocardial infarction," Heart, vol. 96, no. 21, pp. 1710-1715, 2010.

[218] F. Thuny, O. Lairez, F. Roubille et al., "Post-conditioning reduces infarct size and edema in patients with ST-segment elevation myocardial infarction," Journal of the American College of Cardiology, vol. 59, no. 24, pp. 2175-2181, 2012.

[219] X. Freixa, N. Bellera, J. T. Ortiz-Pérez et al., "Ischaemic postconditioning revisited: lack of effects on infarct size following primary percutaneous coronary intervention," European Heart Journal, vol. 33, no. 1, pp. 103-112, 2012.

[220] J.-Y. Hahn, Y. B. Song, E. K. Kim et al., "Ischemic postconditioning during primary percutaneous coronary intervention: the effects of postconditioning on myocardial reperfusion in patients with st-segment elevation myocardial infarction (POST) randomized trial," Circulation, vol. 128, no. 17, pp. 18891896, 2013.

[221] J. T. Lønborg, "Targeting reperfusion injury in the era of primary percutaneous coronary intervention: hope or hype?" Heart, vol. 101, no. 20, pp. 1612-1618, 2015.
[222] K. Przyklenk, B. Bauer, M. Ovize, R. A. Kloner, and P. Whittaker, "Regional ischemic 'preconditioning' protects remote virgin myocardium from subsequent sustained coronary occlusion," Circulation, vol. 87, no. 3, pp. 893-899, 1993.

[223] D. J. Hausenloy and D. M. Yellon, "Remote ischaemic preconditioning: underlying mechanisms and clinical application," Cardiovascular Research, vol. 79, no. 3, pp. 377-386, 2008.

[224] C. Weinbrenner, F. Schulze, L. Sárváry, and R. H. Strasser, "Remote preconditioning by infrarenal aortic occlusion is operative via $\delta 1$-opioid receptors and free radicals in vivo in the rat heart," Cardiovascular Research, vol. 61, no. 3, pp. 591-599, 2004.

[225] T. Rassaf, M. Totzeck, U. B. Hendgen-Cotta, S. Shiva, G. Heusch, and M. Kelm, "Circulating nitrite contributes to cardioprotection by remote ischemic preconditioning," Circulation Research, vol. 114, no. 10, pp. 1601-1610, 2014.

[226] P. Dromparis and E. D. Michelakis, "Mitochondria in vascular health and disease," Annual Review of Physiology, vol. 75, pp. 95-126, 2013.

[227] M. A. Kluge, J. L. Fetterman, and J. A. Vita, "Mitochondria and endothelial function," Circulation Research, vol. 112, no. 8, pp. 1171-1188, 2013.

[228] O. Culic, M. L. H. Gruwel, and J. Schrader, "Energy turnover of vascular endothelial cells," American Journal of Physiology-Cell Physiology, vol. 273, no. 1, part 1, pp. C205-C213, 1997.

[229] Y. Liu, H. Li, A. H. Bubolz, D. X. Zhang, and D. D. Gutterman, "Endothelial cytoskeletal elements are critical for flowmediated dilation in human coronary arterioles," Medical \& Biological Engineering \& Computing, vol. 46, no. 5, pp. 469-478, 2008.

[230] A.-B. Al-Mehdi, V. M. Pastukh, B. M. Swiger et al., "Perinuclear mitochondrial clustering creates an oxidant-rich nuclear domain required for hypoxia-induced transcription," Science Signaling, vol. 5, no. 231, article ra47, 2012.

[231] S.-B. Ong, S. Subrayan, S. Y. Lim, D. M. Yellon, S. M. Davidson, and D. J. Hausenloy, "Inhibiting mitochondrial fission protects the heart against ischemia/reperfusion injury," Circulation, vol. 121, no. 18, pp. 2012-2022, 2010.

[232] S. M. Shenouda, M. E. Widlansky, K. Chen et al., "Altered mitochondrial dynamics contributes to endothelial dysfunction in diabetes mellitus," Circulation, vol. 124, no. 4, pp. 444-453, 2011.

[233] X. Tang, Y. X. Luo, H. Z. Chen, and D. P. Liu, "Mitochondria, endothelial cell function, and vascular diseases," Frontiers in Physiology, vol. 5, article 175, 2014.

[234] M. F. Algahim, S. Sen, and H. Taegtmeyer, "Bariatric surgery to unload the stressed heart: a metabolic hypothesis," American Journal of Physiology-Heart and Circulatory Physiology, vol. 302, no. 8, pp. H1539-H1545, 2012.

[235] B. G. Hill, G. A. Benavides, J. J. R. Lancaster Jr. et al., "Integration of cellular bioenergetics with mitochondrial quality control and autophagy," Biological Chemistry, vol. 393, no. 12, pp. 1485-1512, 2012.

[236] S. W. Ballinger, C. Patterson, C.-N. Yan et al., "Hydrogen peroxide- and peroxynitrite-induced mitochondrial DNA damage and dysfunction in vascular endothelial and smooth muscle cells," Circulation Research, vol. 86, no. 9, pp. 960-966, 2000.

[237] F. Chen, S. Haigh, S. Barman, and D. J. Fulton, "From form to function: the role of Nox4 in the cardiovascular system," Frontiers in Physiology, vol. 3, article 412, 2012. 
[238] B. Lassegue, A. San Martin, and K. K. Griendling, "Biochemistry, physiology, and pathophysiology of NADPH oxidases in the cardiovascular system," Circulation Research, vol. 110, no. 10, pp. 1364-1390, 2012.

[239] S. I. Dikalov, A. E. Dikalova, A. T. Bikineyeva, H. H. H. W. Schmidt, D. G. Harrison, and K. K. Griendling, "Distinct roles of Noxl and Nox4 in basal and angiotensin II-stimulated superoxide and hydrogen peroxide production," Free Radical Biology \& Medicine, vol. 45, no. 9, pp. 1340-1351, 2008.

[240] K. Schröder, M. Zhang, S. Benkhoff et al., "Nox4 is a protective reactive oxygen species generating vascular NADPH oxidase," Circulation Research, vol. 110, no. 9, pp. 1217-1225, 2012.

[241] R. P. Brandes, I. Takac, and K. Schröder, "No superoxideno stress?: Nox4, the good NADPH oxidase!," Arteriosclerosis, Thrombosis, and Vascular Biology, vol. 31, no. 6, pp. 1255-1257, 2011.

[242] F. Veit, O. Pak, B. Egemnazarov et al., "Function of NADPH oxidase 1 in pulmonary arterial smooth muscle cells after monocrotaline-induced pulmonary vascular remodeling," Antioxidants \& Redox Signaling, vol. 19, no. 18, pp. 2213-2231, 2013.

[243] F. J. Sánchez-Gómez, E. Calvo, R. Bretón-Romero et al., "NOX4dependent Hydrogen peroxide promotes shear stress-induced SHP2 sulfenylation and eNOS activation," Free Radical Biology \& Medicine, vol. 89, pp. 419-430, 2015.

[244] C. Schürmann, F. Rezende, C. Kruse et al., "The NADPH oxidase Nox4 has anti-atherosclerotic functions," European Heart Journal, vol. 36, no. 48, pp. 3447-3456, 2015.

[245] F. Paneni, P. Mocharla, A. Akhmedov et al., "Gene silencing of the mitochondrial adaptor p66(Shc) suppresses vascular hyperglycemic memory in diabetes," Circulation Research, vol. 111, no. 3, pp. 278-289, 2012.

[246] C. Napoli, I. Martin-Padura, F. De Nigris et al., "Deletion of the p66Shc longevity gene reduces systemic and tissue oxidative stress, vascular cell apoptosis, and early atherogenesis in mice fed a high-fat diet," Proceedings of the National Academy of Sciences of the United States of America, vol. 100, no. 4, pp. 21122116, 2003.

[247] J. Feng and Z. Zuo, "Isoflurane preconditioning increases endothelial cell tolerance to in-vitro simulated ischaemia," Journal of Pharmacy and Pharmacology, vol. 63, no. 1, pp. 106110, 2011.

[248] A. Beresewicz, M. Maczewski, and M. Duda, "Effect of classic preconditioning and diazoxide on endothelial function and $\mathrm{O}_{2}^{-}$and $\mathrm{NO}$ generation in the post-ischemic guinea-pig heart," Cardiovascular Research, vol. 63, no. 1, pp. 118-129, 2004.

[249] M. W. Broadhead, R. K. Kharbanda, M. J. Peters, and R. J. MacAllister, "KATP channel activation induces ischemic preconditioning of the endothelium in humans in vivo," Circulation, vol. 110, no. 15, pp. 2077-2082, 2004.

[250] S. P. Loukogeorgakis, R. Williams, A. T. Panagiotidou et al., "Transient limb ischemia induces remote preconditioning and remote postconditioning in humans by a KATP channeldependent mechanism," Circulation, vol. 116, no. 12, pp. 13861395, 2007.

[251] D. B. Zorov, M. Juhaszova, and S. J. Sollott, "Mitochondrial ROS-induced ROS release: an update and review," Biochimica et Biophysica Acta, vol. 1757, no. 5-6, pp. 509-517, 2006.

[252] A. K. Doughan, D. G. Harrison, and S. I. Dikalov, "Molecular mechanisms of angiotensin II-mediated mitochondrial dysfunction: linking mitochondrial oxidative damage and vascular endothelial dysfunction," Circulation Research, vol. 102, no. 4, pp. 488-496, 2008.

[253] C. C. Poon, S. W. Seto, A. L. Au et al., "Mitochondrial monoamine oxidase-A-mediated hydrogen peroxide generation enhances 5-hydroxytryptamine-induced contraction of rat basilar artery," British Journal of Pharmacology, vol. 161, no. 5, pp. 1086-1098, 2010.

[254] S. Meresse, M.-P. Dehouck, P. Delorme et al., "Bovine brain endothelial cells express tight junctions and monoamine oxidase activity in long-term culture," Journal of Neurochemistry, vol. 53, no. 5, pp. 1363-1371, 1989.

[255] P. Pagliaro, A. Chiribiri, D. Mancardi, R. Rastaldo, D. Gattullo, and G. Losano, "Coronary endothelial dysfunction after ischemia and reperfusion and its prevention by ischemic preconditioning," Italian Heart Journal, vol. 4, no. 6, pp. 383-394, 2003.

[256] M. N. Sack, "Mitochondrial depolarization and the role of uncoupling proteins in ischemia tolerance," Cardiovascular Research, vol. 72, no. 2, pp. 210-219, 2006.

[257] R. S. Richardson, A. J. Donato, A. Uberoi et al., "Exerciseinduced brachial artery vasodilation: role of free radicals," American Journal of Physiology-Heart and Circulatory Physiology, vol. 292, no. 3, pp. H1516-H1522, 2007.

[258] N. P. Andrews, A. Prasad, and A. A. Quyyumi, "Nacetylcysteine improves coronary and peripheral vascular function," Journal of the American College of Cardiology, vol. 37, no. 1, pp. 117-123, 2001.

[259] T. J. Kizhakekuttu, J. Wang, K. Dharmashankar et al., "Adverse alterations in mitochondrial function contribute to type 2 diabetes mellitus-related endothelial dysfunction in humans," Arteriosclerosis, Thrombosis, and Vascular Biology, vol. 32, no. 10, pp. 2531-2539, 2012.

[260] A. Szewczyk, W. Jarmuszkiewicz, A. Koziel et al., "Mitochondrial mechanisms of endothelial dysfunction," Pharmacological Reports, vol. 67, no. 4, pp. 704-710, 2015. 


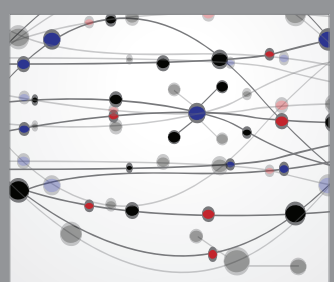

The Scientific World Journal
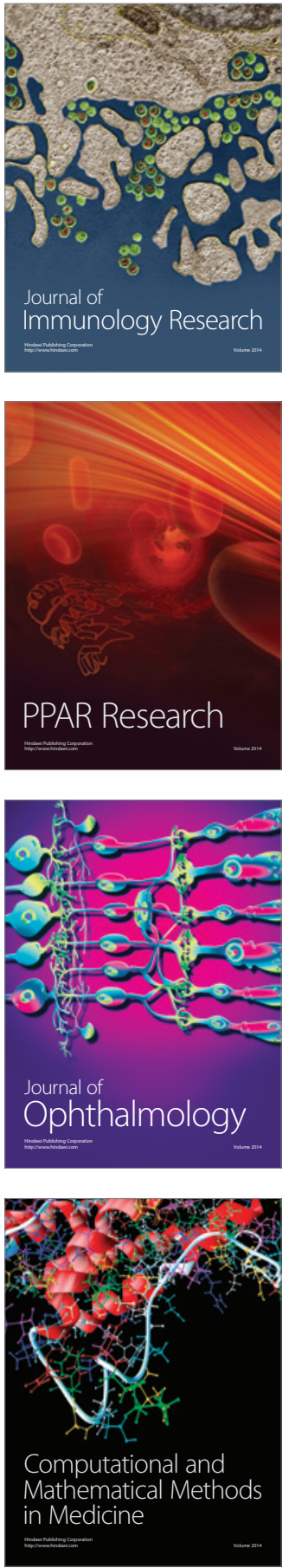

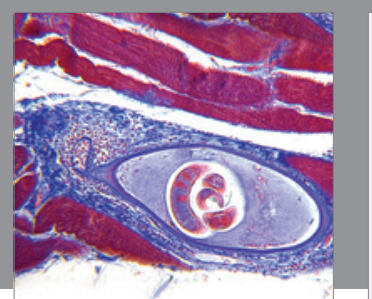

Gastroenterology Research and Practice

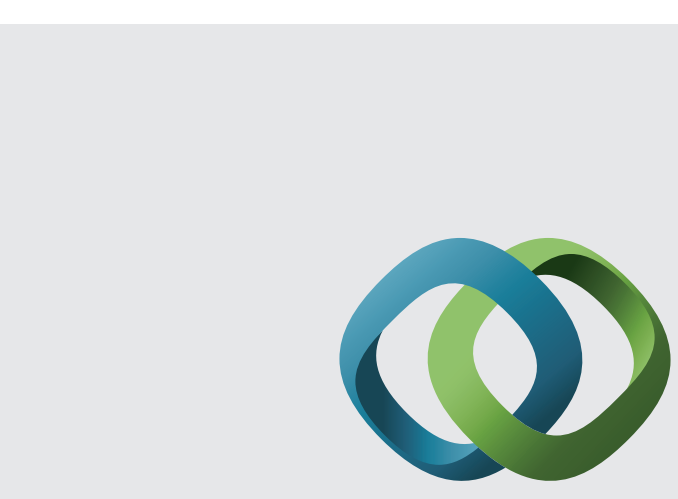

\section{Hindawi}

Submit your manuscripts at

http://www.hindawi.com
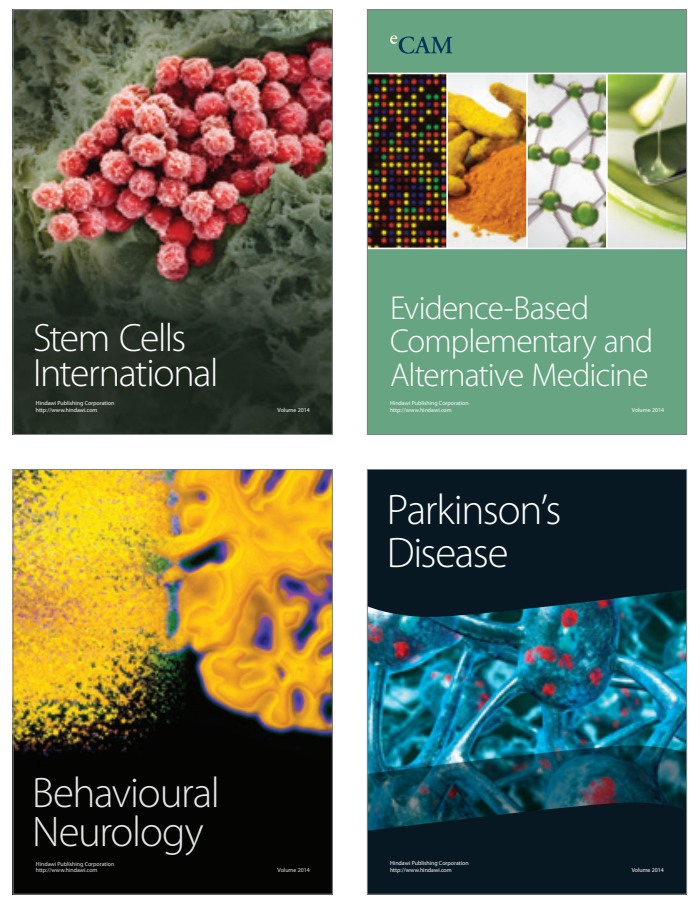
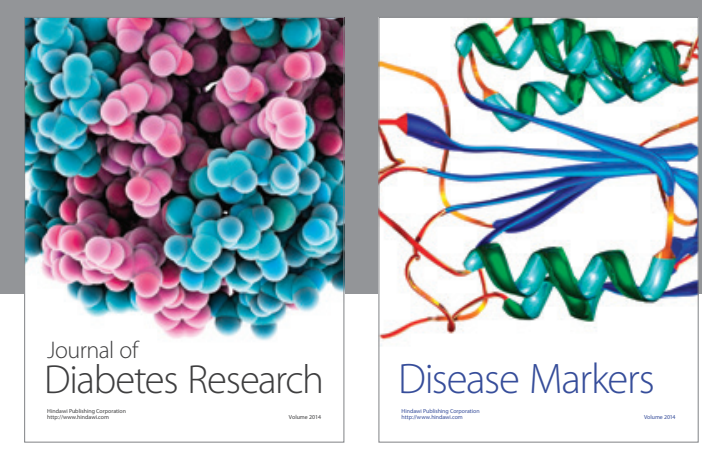

Disease Markers
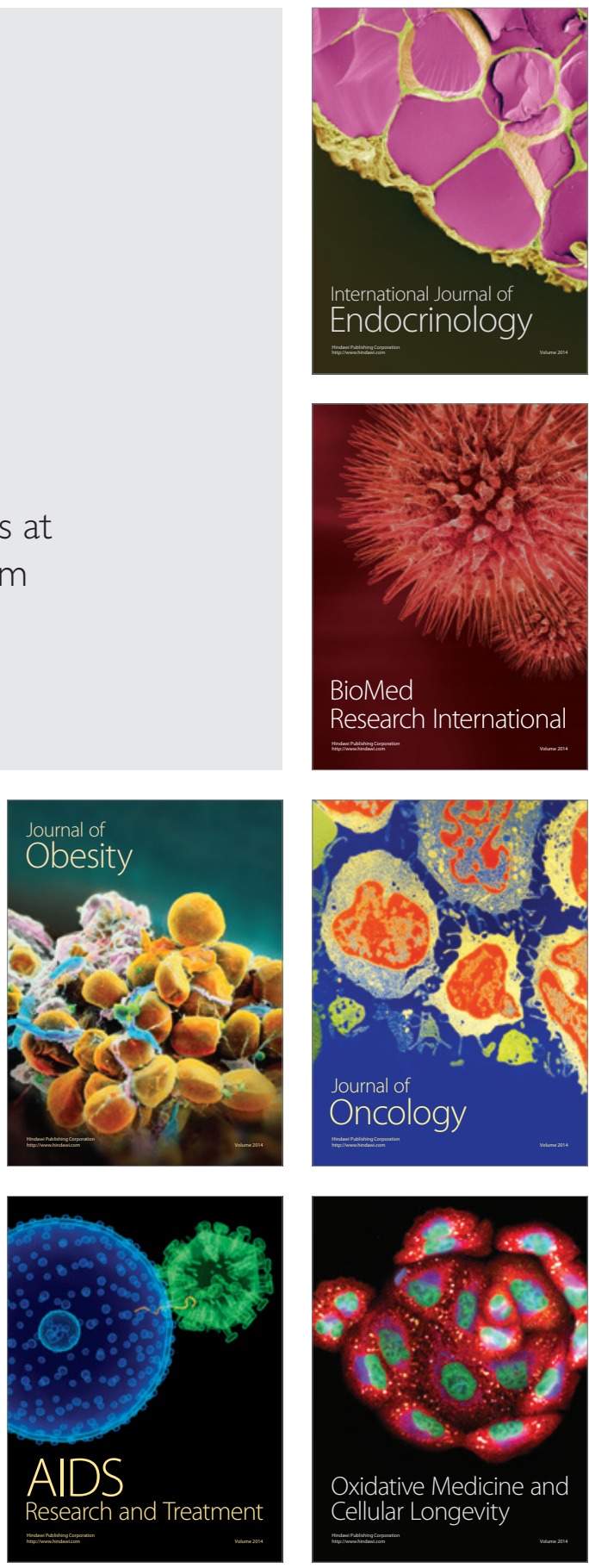